\title{
Literatura peregrina. Kuriose Pilgertexte zwischen Weltlichkeit und Spiritualität
}

\section{Peregrinatio, Neugier und die Weltlichkeit der frühneuzeitlichen Literatur}

Als eine an die Körperbewegung gebundene soziale Ritualpraxis, die sich im Laufe von Spätantike und Mittelalter immer stärker etablierte und ausdifferenzierte, situiert sich die christliche Pilgerschaft ganz natürlich im Spannungsfeld, das sich zwischen dem Heiligen und dem Profanen eröffnet ${ }^{1}$. Einerseits soll der Körper und damit die menschliche Natur im Durchlauf durch die loca sancta die Konstitution einer Pluralität von heiligen Zentren ${ }^{2}$ performativ nachvollziehen und der Flüchtigkeit der Hierophanie durch wiederholende Erfahrung Dauer verleihen. Andererseits muss die körperliche Natur des Menschen als ein Medium zur Sakralisierung bestimmter Orte nach dem christlichen Sündenverständnis immer anfällig und gefährdet sein. Zwischen den heiligen Zentren liegt das Profane praktisch gesehen eben nicht nur als bedeutungslos amorpher Nicht-Ort und «formlose Weite», wie Mircea Elidade formuliert $^{3}$, sondern als verführerische und reizvolle Extension, die der Neugier Nahrung gibt und den Pilger stets dazu verleitet, vom Pilgernden zum

1 Die Forschung zur Ritualpraxis des Pilgerns ist zu umfangreich, um hier einen Überblick liefern zu können. Ich verweise lediglich auf die sehr kurzweilige und kulturübergreifend angelegte Studie von Norman Foster, Die Pilger. Reiselust in Gottes Namen, Frankfurt a. M .: Fischer, 1982, sowie die grundlegende Arbeit von Norbert Ohler, Pilgerstab und Jakobsmuschel. Wallfahren in Mittelalter und Neuzeit, Zürich: Artemis \& Winkler, 2000, und den anthropologischen Ansatz von Edith und Victor Turner, Image and Pilgrimage in Christian Culture, Oxford: Columbia UP, 1978. Zur für den spanischen Kontext besonders relevanten Pilgerschaft nach Santiago de Compostela vgl. außerdem Friederike Hassauer, Santiago: Schrift, Körper, Raum, Reise, München: Fink, 1993, die die performative Ritualpraxis des Pilgerns in ihrer Einbettung in einen den Ritualvollzug «programmierenden» diskursiven Medienverbund rekonstruiert.

2 Die zwar nicht konfliktfreie, aber prinzipiell nicht gefährdete Koexistenz multipler Pilgerschaftszentren im Christentum (mit den drei Hauptzentren Jerusalem, Rom und Santiago de Compostela als Zielen der peregrinationes maiores) spricht für die Richtigkeit der These Mircea Eliades, wonach der Raum des Heiligen durch multiple Zentren gekennzeichnet ist, da jeder Ort des Heiligen sich symbolisch als Zentrum konstituiert. Vgl. Mircea Eliade, Le sacré et le profane, Paris: Gallimard, 1965, S. 43.

3 «Il y a donc un espace sacré, et par conséquent 〈fort», significatif, et il y a d'autres espaces, non-consacrés et partant sans structure ni consistance, pour tout dire: amorphes. Plus encore: pour l'homme religieux, cette non-homogénéité spatiale se traduit par l'expérience d'une opposition entre l'espace sacré, le seul qui soit réel, qui existe réellement, et tout le reste, l'étendu informe qui l'entoure»; Mircea Eliade, Le sacré et le profane (Anm. 2), S. 25, Hervorhebungen dort. 
Irrenden zu werden und sich in der profanen Welt zu verlieren. Die Ausbildung des mittelalterlichen Pilgerwesens war daher von Anfang an begleitet von den mahnenden Warnungen vor den Gefahren seiner Profanierung durch die curiositas $^{4}$. Dem Vollzug der Pilgerschaft als Ritualpraxis und begleitenden apologetischen Diskursen stand daher schon rasch und spätestens mit Augustin bereits voll ausgebildet eine Gegenkonzeption spiritueller Pilgerschaft gegenüber, die nicht auf Körperperformanz, sondern auf asketische Selbstpraxis und vor allem auf die hermeneutische Auslegung der heiligen Schrift abzielt. Sie hat weniger Vertrauen in das schwache Medium des Körpers und versucht daher, dessen Einfluss und Spielraum im Nachvollzug des Heiligen so weit wie möglich zu minimalisieren. Ritualpraxis und der Gedanke einer Pilgerschaft im Geiste hielten sich dabei das ganze Mittelalter hindurch in einer instabilen, aber funktionierenden Balance ${ }^{5}$. Die populäre Pilgerschaftspraxis, in der das Sakrale und das Profane durch ihre metonymische Nähe in der Welt stets mischungsanfällig sind und enorme Affektenergien zur Aufrechterhaltung und ständigen dynamischen Neuerrichtung entsprechender trennender Schwellen erfordern, benötigte das Korrektiv eines strengen Ideals spiritueller Pilgerschaft im Geiste, hin zum Wort, das Christus ist.

Mit Beginn der Frühen Neuzeit geriet diese Ausgleichsdynamik aber an ihre Grenze, aus vor allem zwei systemischen Gründen: Zum einen führte die empirische Expansion der Welterkenntnis im Zuge der Kolonialisierung zu einer Anreicherung von weltlichen Reizen, die das Profane nicht einfach nur quantitativ verstärkte, sondern ihm eine neue Qualität, die des Wunderbaren und Fremden, verlieh, bevor das Neue dann allmählich rationalisiert werden und mit Hilfe entsprechender Vermessungstechniken (Kartographie, Geographie etc.) in eine neue, globalisierte Raumkonzeption integriert werden konnte $^{6}$. Die tradierten Zentren der christlichen peregrinatio waren nicht mehr

4 Beispielhaft dafür ist die Kritik der Kirchenväter Hieronymus und Gregor von Nyssa. So warnte Hieronymus in seiner Epistula ad Paulinum presbyterum vor dem Versuch, Gott, dessen Geist weht, wo er will, irdisch verorten zu wollen: «non Hierosolymis fuisse, sed Hierosolymis bene uixisse laudandum est [...] et ueri adoratores neque Hierosolymis neque in monte Garizin adorant patrem, quia deus spiritus est et adoratores eius in spiritu et ueritate adorare eum oportet. Spiritus autem spirat, ubi uult. Domii est terra et plenitudo eius [...] et de Hierosolymis et de Britannia aequaliter patet aula caelestis; regnum enim dei intra nos est» (Sancti Eusebii Hieronymi Epistulae, Wien: Verlag der Österreichischen Akademie der Wissenschaften, ${ }^{2}$ 1996, Bd. 1, Epistula LVIII, S. 527-541, hier S. 529 ff.). Zur Pilgerschaftskritik bei Gregor von Nyssa vgl. außerdem Bernhard Kötting, «Gregor von Nyssas Wallfahrtskritik», in: B. K., Ecclesia peregrinans. Das Gottesvolk unterwegs, Münster: Aschendorf, 1988, Bd. 2, S. 245-251.

5 Zur Balance zwischen Lob und Tadel der Pilgerschaft und der Ausbildung eines monastischen Konzeptes einer peregrinatio in stabilitate im Spätmittelalter vgl. insbesondere Klaus Schreiner, «Peregrinatio laudabilis und peregrinatio vituperabilis. Zur religiösen Ambivalenz des Wallens und Laufens in der Frömmigkeitstheologie des späten Mittelalters», in: Wallfahrt und Alltag in Mittelalter und Früher Neuzeit, Wien: Verlag der Österreichischen Akademie der Wissenschaften, 1992, S. 133-163.

6 Paradigmatisch zeigt sich die allmähliche Rationalisierung des Wunderbaren im Funktionswandel des Reiseberichtes. Vgl. dazu José Manuel Herrero Massari, «La percepción de la 
nur von der Gefahr des Abschweifens im zu überbrückenden Zwischenraum bedroht, sondern von den mirabilia einer «neuen» Welt, die dank des Buchdrucks vor allem in Form von exotistischen Illustrationen in die alte kam und nicht bruchlos in die tradierten Wissenssysteme zu integrieren war $^{7}$. Die geographische Welt hatte sich so plötzlich erweitert, dass sie im christlichen Weltbild einfach nicht mehr zu fassen war. Der zweite einschneidende Grund für die Destabilisierung der mittelalterlichen peregrinatio-Konzeption in der Frühen Neuzeit ist das kirchliche Schisma innerhalb der christlichen Religion. Mit der im Zuge des Konzils von Trient vollzogenen dogmatischen Scheidung zwischen Katholizismus und Reformation musste jede allzu scharfe spirituelle Kritik an der Ritualpraxis des Pilgerns im Lager des Katholizismus automatisch in den Verdacht des Heterodoxen geraten. Dort stellte sich damit das Problem, ob und wie ein neues Korrektiv zur lebensweltlichen Pilgerpraxis zu schaffen wäre, das die Funktion der evangelisch inspirierten Kritik an einer Veräußerlichung der Religion übernehmen könnte, wie sie vor dem Schisma vor allem der erasmistisch beeinflusste Humanismus geleistet hatte, die durch Luther aber zu einem Element des Protestantismus geworden war und damit keine legitime Möglichkeit mehr im Rahmen der Orthodoxie darstellte.

Vor dem Hintergrund dieser kulturgeschichtlichen Problematik stellt sich die Frage, wie die bemerkenswerte Prominenz der peregrinatio-Konzeption in der spanischen Erzählliteratur des Siglo de Oro einzuschätzen ist. Eine vor allem im Blick auf Lope de Vegas Peregrino en su patria und Cervantes' Trabajos de Persiles y Sigismunda häufig vertretene These geht davon aus, dass die Literarisierung der Pilgerschaft eine dogmatisch-orthodoxe Funktionalisierung der Literatur im kontroverstheologischen Geiste des Tridentinums bedeutet $^{8}$, also eine theologische Überformung der Profanliteratur. Eine

maravilla en los relatos de viajes portugueses y españoles de los siglos XVI y XVII», in: Rafael Beltrán (Hrsg.), Maravillas, peregrinaciones y utopías, Valencia: Universitat de València, 2002, S. 291-305.

7 Symptomatisch für diesen Bruch zwischen alter christlicher Kosmologie und den «neuen〉 Mirabilia ist Mandevilles Reisebericht, der sich gar nicht erst darum bemüht, eine glaubwürdige Vermittlung zwischen religiösem Pilgerschaftsritual und profaner Neugier zu leisten. In Otto von Diemeringens deutscher Übersetzung von 1484 heißt es zum Auftakt des anderen Buchs: «Nun, da ich euch von dem Heiligen Land und den Wegen, die dahin führen, erzählt habe, will ich von den Landen, Tieren und Menschen jenseits der Heiligen Stätten berichten» (John Mandeville, Land, Indien und China, hrsg. v. Theo Stemmler, Stuttgart: Steingrüben, 1966, S. 95). Stephen Greenblatt spricht angesichts dieses plötzlichen Wechsels von «an abandonement of the dream of a sacred center upon which all routes converge and a turning instead toward diversity, difference, the bewildering variety of 〈marvellous things»» (Stephen Greenblatt, Marvellous Possessions. The Wonder of the New World, Oxford: Clarendon, 1991, S. 29).

8 «[...] es un hombre de la Contrarreforma» stellte etwa Antonio Vilanova rundheraus fest, wobei er das Liebespaar des cervantinischen Romans zur Singulargestalt eines idealtypischen Pilgers abstrahiert; vgl. «El peregrino andante en el Persiles de Cervantes», in: Boletín de la Real Academia de buenas letras de Barcelona 22 (1949), S. 97-159, hier S. 101. Zum Einfluss der tridentinischen Dogmatik auf Lope de Vegas Roman vgl. besonders 
These, die selbstverständlich heterodoxe Gegenlektüren herausfordert, wie sie für den Persiles erst kürzlich Michael Nerlich in einer monumentalen Studie geleistet hat ${ }^{9}$. Es kann aber bezweifelt werden, ob das Verhältnis der Literatur zum Heiligen - und nicht weniger steht mit dem Einsatz des Pilgerschaftsgedankens auf dem Spiel - überhaupt sinnvoll im Rahmen einer einfachen binären Opposition zwischen Orthodoxie und Heterodoxie geklärt werden kann. Sowohl die gegenreformatorische Lesart als auch die sie bestreitende Gegenposition setzen im Grunde voraus, dass die Doxa des Konzils von Trient im frühneuzeitlichen Spanien als entscheidende Normierungsinstanz des Sakralen angesetzt werden können und dass die Weltlichkeit der Literatur aus dem Grad ihrer Affirmation oder Negation dieser Instanz resultiert. Gegen ein solches binäres, zur Entscheidung nötigendes Modell, gehen meine eigenen Überlegungen davon aus, dass die Grenze zwischen Heiligem und Profanen historisch dynamisch und kulturpragmatisch flexibel verläuft und dass das Konzil von Trient diese grundlegende Flexibilität nicht prinzipiell still stellen konnte. Auch und gerade in der gegenreformatorischen Kultur Spaniens stand das Sakrale nicht einfach fest, sondern musste immer wieder neu normativ ausgehandelt werden, wobei sich zwischen den weltlichen machtpolitischen Interessen des Staates und der Dogmenbildung der Kirche als den beiden Hauptakteuren des Normbildungsprozesses trotz ihres ideologischen Zusammenwirkens auch immer wieder Interessenkonflikte und Reibungspunkte ergaben. Philipp II., der nicht zögerte, in seinem Herrschaftsbereich die Beschlüsse des Konzils als Gesetze verbindlich in Kraft zu setzen, war genauso entschlossen, die Möglichkeiten zur Kontrolle der Literatur nicht der Kirche zu überlassen, sondern für sich zu reklamieren. In einem Dekret von 1558 wurde die Macht zur Vergabe von Druckerlaubnissen als Vorrecht der Krone festgelegt ${ }^{10}$, ein Gesetz, auf dessen Grundlage ein eigenes staatliches Zensursystem errichtet wurde, das - anders als in Portugal und Italien - die Zensurkriterien der päpstlichen Inquisition nicht einfach übernahm, sondern eigene Indices erarbeitete, auch wenn dabei selbstverständlich die Normen der Kirche nicht unbeachtet blieben. Die Zensurforschung hat gezeigt, dass diese relative Autonomie der staatlichen Zensur dafür sorgte, dass die spanische Profanliteratur im ausgehenden 16. Jahrhundert einen vergleichsweise großen

Paul Descouzis, «Filiación tridentina de Lope de Vega: El Peregrino en su patria» (1604)», in: Revista de estudios hispánicos 10 (1976), S. 125-138.

9 Michael Nerlich, Le «Persiles» décodé ou la «Divine Comédie» de Cervantes, ClermontFerrand: PU Blaise Pascal, 2005. Die teilweise polemisch geführte Auseinandersetzung mit der gegenreformatorischen Lesart des Textes, die Nerlich als herrschende katholische Doxa darstellt (insbes. S. 51-55), durchzieht die ganze Studie, die sich selbst daher als eine heterodoxe Gegenlektüre versteht.

10 Vgl. dazu Antonio Sierra Corella, der die entscheidenden Passagen transkribiert: La censura de libros y papeles en España y los indices y catálogos españoles de los prohibidos y expurgados, Madrid: Góngora, 1947, S. 96-99. 
Spielraum behielt ${ }^{11}$. Literarische Fiktion wurde nicht zu einem bloßen Instrument der Dogmatik konvertiert, sondern schärfte unter dem Druck der Dogmatik ihren Status als eines zwar nicht normfreien, aber durch funktionale Unterbestimmtheit nicht eindeutig normierten in between, eines Reiches des Zwischen, in dem die kulturpragmatische und historisch dynamische Grenze zwischen dem Heiligen und dem Profanen nicht entschieden, sondern beobachtbar gemacht und dabei zugleich problematisierbar wird. Zum Beleg dieser Behauptung sollen paradigmatisch drei unterschiedliche Stränge der literarischen Ausgestaltung der Pilgerschaftskonzeption an Texten diskutiert werden, die alle im ausgehenden 16. Jahrhundert entstanden sind und aus unterschiedlichen Gründen nicht zum heutigen hispanistischen Kanon gerechnet werden können: Bartolomé de Villalba y Estañas Peregrino curioso y grandezas de España, Jerónimo de Contreras' Selva de aventuras und schließlich Fernão Mendes Pintos Peregrinação. Ich werde an diesen Beispielen keine epochale geschichtsphilosophische These erarbeiten, sondern vielmehr $\mathrm{zu}$ zeigen versuchen, dass die funktionale Offenheit des Mediums Literatur sich solcher Thesenbildung entgegenstellt und zu pragmatischer Differenzierung je nach Einzelfall nötigt. Gerade in der ersten Phase der Gegenreformation, in dem das Verhältnis von Profanliteratur und kontroverstheologisch abgesichertem dogmatischem Wissen um das Heilige mit Hilfe der Indizierungen geregelt werden sollte, konnte der profanen Literatur keineswegs ein eindeutiges Verhältnis zum Heiligem vorgeschrieben werden, sondern blieb die Grenze zwischen fanum und profanum in der Literatur flexibel und durchlässig. Festzustellen ist dabei bereits auf der Ebene der Steuerung der Literatur durch die Zensur ganz grundsätzlich eine Gleichzeitigkeit von Aufund Abbau der Schwelle zum Sakralen, was deshalb nicht paradox ist, weil beide Bewegungen unterschiedlichen, aber koexistierenden und gemeinsam agierenden Konstitutionslogiken folgten: Aus der Sicht der katholischen Dogmatik sollte die Profanliteratur einerseits klar als profane erkennbar bleiben und sich nicht in das von ihr gehütete sacrum einmischen. Man wollte auf jeden Fall eine ungesteuerte volkssprachliche Verbreitung der heiligen Schrift

11 Das relativ moderate Vorgehen der spanischen Zensurbehörden (das allerdings nicht für den Theaterbereich gilt) zeigt sich exemplarisch an den Unterschieden zwischen dem Index von Quiroga (1583/84) zum wesentlich strengeren portugiesischen Index von 1581, der eine ganze Reihe von Titeln enthält, die von Quiroga unbeanstandet blieben (Fernando de Rojas Celestina, Ovids Metamorphosen, Apuleius' Asinus Aureus, etc.). Symptomatisch ist auch die Tatsache, dass die moralische Verbotsbegründung in der siebten regula des Tridentiner Index (1664) nicht übernommen wurde. Vgl. dazu Peter E. Russell, «El concilio de Trento y la literatura profana: reconsideración de una teoría», in: P. E. R., Temas de «La Celestina» y otros estudios. Del «Cid» al «Quijote», Barcelona: Ariel, 1978, S. 441-478, sowie Gwyn E. Campbell, «The Tridentine Index, Quiroga's Index, and Gómez de Castro's parecer: A Commentary on the Censorship of secular literature in Spain», in: Hispanófila Nr. 106 (1992), S. 11-21. Einen Überblick über die Forschung zur spanischen Inquisition bieten außerdem Antonio Márquez, Literatura e inquisición en España (1478-1834), Madrid: Taurus, 1980, sowie Ángel Alcalá, Literatura y ciencia ante la inquisición española, Madrid: Laberinto, 2001. 
und nicht-konsakrierter Auslegungen verhindern, wie man sie der evangelischen Seite als Profanierung anlastete ${ }^{12}$. Deshalb gerieten ja auch konsequente und gut gemeinte Versuche zur Ausbildung einer sakralisierenden literatura a lo divino in das Visier der Zensur, wie der Fall von Jerónimo de San Pedros Caballería celestial zeigt ${ }^{13}$. Andererseits durfte, ja sollte die Profanliteratur aber durchaus katholische Gesinnung zeigen, um den Bestrebungen der spanischen Monarchie, sich im Verbund mit der ecclesia militans als Wahrerin einer tradierten Sakralordnung zu stilisieren, nützlich sein zu können. Nötig wurde daher eine Art katholischer Profanliteratur, ein Terminus, der nicht gerade durch konzeptuelle Stringenz besticht, aber gerade in dieser Schwäche ganz gut den hybriden Charakter der Werke beschreibt, die de facto im posttridentinischen in between zwischen Heiligem und Profanem, zwischen theologisch-orthodoxer Dogmatik und machtpolitischer Pragmatik entstanden.

12 Die systematischen inquisitorischen Maßnahmen gegen die evangelische «Gefahr» volkssprachlicher Bibelversionen dokumentiert Alcalá, Literatura y ciencia ante la inquisición Española (Anm. 11), S. 60-70. Er vermutet dabei den «tradicional recelo antijudaico» als einen Hauptgrund, der im Zuge der dogmatischen Abwehr gegen die protestantische Häresie noch verstärkt worden sei (S. 62).

13 Jerónimo de San Pedros Buch wurde als eines der wenigen volkssprachlichen Prosawerke schon in den Index von Valdés 1559 aufgenommen und blieb seither verboten. Menéndez y Pelayo sah dieses Verbot im unfreiwillig sakrilegischen Charakter des Werkes begründet, das Christus und seine Jünger als Ritter auftreten lässt (vgl. Orígenes de la novela, hrsg. v. Enrique Sánchez Reyes, Santander: CSIC, 1943, Bd. 1, S. 448). Dass der Autor mit seiner Travestierung der Heiligen Schrift dabei keine blasphemischen, sondern eine evangelisierende Absicht verfolgte, wird aus seinem Einleitungsschreiben «al beneuolo lector» ganz zweifellos deutlich: "Tan estragados estan los gustos de nuestros tiempos, letor piadoso, por el acidente de frialdad, que el estomago dela charidad padece, y tan acostumbrados alos terrenos manjares, para saberles bien la comida espiritual, que siendo dulce y prouechosa vianda la leccion dela diuina escriptura, la dan de mano, y la dexan por desabrida. Admiten el pasto de las letras profanas por sabroso, y alabanlo por delicado» (Libro de Caualleria Celestial del pie de la Rosa Fragante, dedicado al ilustrißismo y reuerendißismo señor don Pedro Luy Galceran de Borja Maestre del Orden y Caualleria de nuestra Señora de Montesa y de San George, Antwerpen: Martin Nucio, 1554, fol. 3 ro). Man braucht diesen frommen Versuch zur schmackhaften Darreichung des Lebens Christi als Ritterroman aber wegen seines Scheiterns nicht unbedingt als Naivität (Menéndez y Pelayo spricht von «cándida irreverencia») verunglimpfen. Dass die Wertungskriterien der Inquisition zur Bewahrung des Heiligen nicht eben leicht durchschaubar waren, muss der Kritiker, der als Autor einer Historia de los héterodoxos españoles als Spezialist in Fragen der Orthodoxie gelten darf, an anderer Stelle selbst einräumen. Der Kommentar Cesárea Banderas zum Verbot der Caballería celestial dürfte die Sachlage deshalb zutreffender bezeichnen: «Obviously, the Inquisitors were not amused by such a clumsy intent to play with the sacred, even with the best intentions. It was one thing to use poetry strictly as a servant of the sacred, and quite another to dress the sacred in the servant's clothes to make it attractive and, thus, in some way, to bring it down to the servant's level. Two very different things indeed, both from the point of view of doctrine and of poetry, but the line between the two was, nevertheless, rather thin, the danger of a faux pas great. It took an excellent poetic intuition (such as Calderón's) to walk on such dangerous high wire without falling» («Seperating the human from the divine», in: Contagion: Journal of Violence, Mimesis and Culture 1 (1994), S. 73-90, hier S. 80). 


\section{Die neugierige Verweltlichung des Pilgerrituals: Bartolomé de Villalba y Estañas Peregrino curioso y grandezas de España}

Schon der Titel dieses Textes, der 1577 licencia und approbatio erhielt, aber nie veröffentlicht wurde ${ }^{14}$ und heute nur in Fragmenten in einer sehr raren Neuedition aus dem späten 19. Jahrhundert zugänglich ist ${ }^{15}$, ist peregrino im erweiterten, spezifisch neuzeitlichen Sinne des Terminus, wie ihn Covarrubias nach Erwähnung der Grundbedeutung als romería festhält, nämlich eine seltsame und befremdliche Angelegenheit, «una cosa rara» ${ }^{16}$. Die Zusammenführung von Pilgerschaft und curiositas, die bei Augustinus geradezu den Rang einer Todsünde einnimmt ${ }^{17}$, hätte nicht nur in den Ohren von Erasmus

14 Von den angekündigten zwanzig Büchern des peregrino curioso, zu denen der Autor auch schon eine Inhaltsübersicht abliefert, sind nur die ersten acht erhalten. Victoria Campo spekuliert, dass Villalba y Estaña eine Art Vorab-Druckerlaubnis erwirken konnte, dann aber sein Werk nicht vollendet habe; vgl. «De lectores y lecturas: la Respuesta de Fr. Tomás Quixada en El peregrino curioso de Bartolomé de Villalba», in: Ignacio Arellano u. a. (Hrsg.), Studia aurea, Pamplona: GRISO, 1996, Bd. 1, S. 247-256, hier S. 248, Anm. 8. Angesichts des üblichen Lizenzierungsverfahrens, das die Vorlage des kompletten Manuskripts verlangte, scheint diese Hypothese allerdings nicht sehr wahrscheinlich. Vgl. zur Textgeschichte José María Pérez y Martín, Cartas del «Doncel de Xérica» al Rey Felipe III, con un estudio bio-bibliográfico, Castellón: Sociedad Castellonense de Cultura, 1922, S. 69-75.

15 Es handelt sich um die Ausgabe von Pascal de Gayangos, die leider nicht den Kriterien einer kritischen Edition entspricht, aber heute praktisch die einzige Zugriffsmöglichkeit auf den Text darstellt. Nach ihr wird im Folgenden zitiert. Das einzige erhaltene Manuskript, von dessen Fund erstmals Ticknor in seiner spanischen Literaturgeschichte berichtete, ist in der Bibliothek von Santa Cruz de Valladolid aufbewahrt.

16 «PEREGRINO. El que sale de su tierra en romería a visitar alguna casa santa o lugar santo. Díjose en latín PEREGRINUS, a peregre, hoc est longe, por andar largo camino. 2. Peregrinar, andar en romería o fuera de su tierra. 3. Peregrinación, la romería. 4. Cosa peregrina, cosa rara»; vgl. Sebastián de Covarrubias Orozco, Tesoro de la lengua castellana o española (1611), Madrid: Castalia, ${ }^{2} 1995$, S. 814). Michael Nerlich, der Covarrubias sonst als Hauptquelle zur Rekonstruktion des Wissenshorizontes des spanischen Lesers zur Zeit Cervantes einsetzt, versucht jedoch genau diesen Eintrag zu entautorisieren und bezweifelt mit Hilfe des entsprechenden Lemmas aus dem Vocabularium ecclesiasticum von Rodrigo Santa Ella (1596), dass die theologisch-religiöse Bedeutung des Terminus um 1600 tatsächlich noch vorrangig gewesen sei; vgl. Le «Persiles» décodé (Anm. 9), S. 256. Ein an dieser Stelle etwas forcierter und methodisch überflüssiger Versuch, sich der katholisch-gegenreformatorischen Interpretationslinie entgegenzustellen, denn den Grad der Orthodoxie einer literarischen Funktionalisierung des Pilgerschaftskonzeptes wird man nicht ernsthaft an der Lexikalisierung der Wortbedeutung ablesen wollen (und Nerlich versammelt eigentlich auch ausreichend inhaltliche und strukturelle Argumente für seine Lektüre, um auf derartige Forcierungen verzichten zu können). Unabhängig von den möglichen lexikographischen Hierarchisierungen zwischen religiöser und profaner Semantik der Pilgerschaft ist für die neuzeitliche Situation einzig die Polyvalenz, die zwischen beiden Feldern entsteht, entscheidend. Sie wurde in der spanischen Literatur reichlich genutzt und besaß zur Zeit des Persiles schon fast topischen Charakter. Zum Einsatz der unterschiedlichen Semantiken von «peregrino» im Persiles vgl. Nadine Ly, «Le miroitement de la vraisemblance», in: Les langues néo-latines Nr. 327 (2003), S. 39-72, bes. S. 63-71.

17 Insbesondere in den Confessiones V, 3 und X, 35. Zur Geschichte der curiositas als ästhetischer Kategorie vgl. Barbara Vinken, «Curiositas/Neugierde», in: Ästhetische Grund- 
oder Luther wie eine offene Profanierung geklungen, sondern wäre bei Veröffentlichung wohl auch von den Ordnungskräften missbilligt worden, die sich im gegenreformatorischen Spanien nicht zuletzt auch in Reaktion auf die reformatorische Kritik um eine striktere Kontrolle des Pilgerwesens und seinen Schutz vor Missbrauch bemühten. Es ist deshalb kaum überraschend, dass dem Text eine Tendenz zur Selbstlegitimation eingeschrieben ist. Von Anfang an stellt der Autor sein Schreiben als ein gefährdetes und keineswegs selbstverständliches Unternehmen aus: Im Haupttext zeigt sich das in den mehrfachen Warnungen vor der kontrollierenden justicia an die Adresse des neugierigen Pilgers ${ }^{18}$, paratextuell am Gutachten des Prämonstratenserpaters Fray Tomás Quixada, das sich der Autor als vorbeugende Maßnahme gegen mögliche Kritik einholt. Die consulta gerät zu einem fast 300 Werke und 60 Seiten umfassenden gereimten Katalog kritisierter, schlecht beleumundeter oder gar zensierter Werke des 16. Jahrhunderts, der beweisen soll, dass übelwollender Kritik bei bestem Willen nicht zu entgehen ist und Einwände von Seiten der murmuradores, die jede Form der Literatur zu treffen scheinen, egal ob sie profanen oder sakralen Charakter hat, daher nicht als Makel sondern eher als Auszeichnung verstanden werden müssen:
Y si mi voto vale para en algo
sacalde á luz, que no os digo lisonjas, que en fé de religioso y buen hidalgo que os le agoten los frailes y las monjas, y cualquier hombre que presuma algo le mercará y áun digo que en las lonjas adonde la virtud no tiene asiento, á platicos dará sumo contento (S. 70).

Als Cervantes-Kenner wird man im Familiennamen des belesenen Geistlichen, der im Don Quijote als ein Element im burlesken Verwirrspiel um die Identiät des Protagonisten eingesetzt ist ${ }^{19}$, vielleicht ein raffiniertes Ironiesignal vermuten; gegen eine ironische Lektüre des Textes spricht aber das ganze übrige Werk, soweit es uns erhalten ist. Villalba y Estaña gestaltet seine Erzählung über weite Strecken als Kolportageliteratur voller mittelalterlicher Mirakel-, Schwank- und Schauerelemente und setzt insgesamt auf möglichst direkte Effekte, was zwar Komik einschließt, aber nicht die indirekte Form des

begriffe, hrsg. v. Karlheinz Barck, Stuttgart/Weimar: Metzler 2000-2005, Bd. 1, S. 794813.

18 Bartolomé de Villalba y Estaña, El peregrino curioso y Grandezas de España, hrsg. v. Pascual de Gayangos, Madrid: Sociedad de Bibliofilos Españoles, 2 Bde., 1886 u. 1889. Ein erster Hinweis auf die Justiz S. 93, dann S. 142; die Schwierigkeit einer Unterscheidung von «authentischen» und falschen Pilgern wird außerdem auf S. 390 f. thematisiert.

19 Quijada ist neben Quijano und Quesada eine der möglichen Namensformen des Protagonisten vor seiner Ritterwerdung und Verwandlung zu Don Quijote. Zu Cervantes' ironischem Spiel mit der Namensidentität seines 〈Helden〉 vgl. Horst Weich, Don Quijote im Dialog, Zur Erprobung von Wirklichkeitsmodellen im spanischen und französischen Roman (von «Amadis de Gaula» bis «Jacques le fataliste»), Passau: Rothe, 1989, S. 57-62. 
Ironischen. Und auch ideologisch ist das im Text artikulierte Verhältnis zur kirchlichen und weltlichen Obrigkeit und den sozialen Wertenormen seiner Zeit ungebrochen affirmativ und wird als solches immer wieder ausgestellt ${ }^{20}$. Ironisch ist der Text also nicht auf der Ebene der intentio auctoris ${ }^{21}$, sondern allenfalls in seiner Wirkung im Wertehorizont eines durch aufgeklärte Vernunft geprägten Rezipienten. In der auktorialen Perspektive bilden Devotion und eine bisweilen zu offenem Voyeurismus und aggressiven Sadismus regredierende Neugier jedenfalls keinen Widerspruch, sie laufen vielmehr von Anfang an konsequent und störungsfrei nebeneinander. «Pareciole tomar trage $\mathrm{y}$ habito de Pelegrino, para por una parte saciar su animo de ver, y por otra su devocion de andar las muchas casas que en España hay tan principales» (S. 84) heißt es so zur Begründung der Pilgerschaft. An anderer Stelle verteidigt der Protagonist explizit sein Interesse an profanen höfischen Liebesgeschichten mit dem Hinweis auf seine eigene Position, die als eine Äquidistanz zwischen sanctum und profanum dargestellt wird:

[...] no quiero que me tengais por tan santo que eso me ofenda los oidos, ni por tan profano que me huelgue de tratar cosas ilicitas; mas en materia de amor y de las damas, sin dar en el un estremo ni en el otro, como buenos cortesanos, podreis decir cosas apacibles para discretos, ejemplares para virtuosos, de admiración para los prudentes, de espanto para los poco cursados (S. 160).

Beide Antriebe, Devotion und Neugier, bleiben als parallellaufende Motive den gesamten Text hindurch erzählerisch wirksam, wobei die Devotionslogik vor allem strukturgebenden Charakter hat und das Reiseitinerar und die Auswahl der beschriebenen Örtlichkeiten bestimmt ${ }^{22}$, die Neugier dagegen die vielen Geschichten motiviert, die an den Orten des Heiligen erzählt werden, rein quantitativ dominiert und den Leseprozess affektiv, durch Rätsellust und

20 Der Gestus der Unterwerfung unter die kirchlichen und weltlichen Autoritäten wird nicht nur im paratextuellen Vorraum zum Erzählen wirksam, sondern auch im Haupttext immer wieder bekräftigt. Als ein Beispiel sei hier nur das panegyrische Sonett auf den Infanten Fernando genannt, dem der Text zunächst auch gewidmet werden sollte, was durch dessen frühen Tod im Oktober 1578 im Alter von sieben Jahren dann jedoch hinfällig wurde: «Hernando, Príncipe de España honrosa, / rebiznieto de Hernando, Rey preclaro, / la obligacion que tienes no declaro, / que dificil será tan alta cosa. / Una cosa me escucha provechosa, / que si imitar querrás al abuelo raro, / que sujetó á Granada sin reparo, / será tu fama eterna y muy gloriosa. / No hay Marte, no hay Vulcano, no hay Apolo, / tan raro como Carlos V ha sido, / tu abuelo, que el plus ultra te ha dejado. / Si quieres ser tenido y ser hoy solo, / imita á tus abuelos, que han tenido/ la vida igual al nombre que han dejado» (S. 151).

21 Zur Unterscheidung von intentio auctoris, intentio lectoris und intentio operis als unterschiedlichen Interpretationstypen vgl. Umberto Eco, I limiti dell'interpretazione, Milano: Bompiani, 1990, S. 22-25.

22 Zum Reiseitinerar des Peregrino curioso vgl. Victoria Campo, «Acerca del itinerario de El peregrino curioso (1577) de Bartolomé de Villalba», in: Caminería Hispánica, Guadalajara: Aache, 1996, Bd. 3, S. 197-204. Wertvolle Anregungen bot mir außerdem ein Vortrag von Françoise Crémoux über «L'imaginaire sacré de l'Espagne dans Pelegrino curioso y grandezas de España», der auf einem Symposium in der Casa de Velázquez zum Thema L'imaginaire du territoire (20.-22. Februar 2006) in Madrid gehalten wurde. 
Spannung, vorantreibt ${ }^{23}$. Das Devotionsinteresse, das in der begründenden Produktionslogik des Textes die curiositas formal und strukturell an Orte des Heiligen bindet und in dieser Bindung legitimiert, ist für die angemessene Rezeption des Textes, wie sie Villalba y Estaña im Vorwort entwirft, allerdings keine notwendige Voraussetzung mehr, sondern lediglich eine von vielen Optionen, die dem individuellen gusto des Lesers überlassen bleiben. Notwendig ist allein die Neugier, ohne die der Text seinen Unterhaltungszweck verfehlen müsste:

Pidote le leas como curioso. A nuestra Santa Madre Iglesia en todo y por todo le sujeto, á los sábios le rindo y al lector encargo que sea abeja, y no arañe: que en estos veinte libros para viejos hay que escuchar, y para curiosos que notar, y para devotos que oir, y para mozos que leer; y si en diversidad de gustos de alguno fuere repudiado el Pelegrino, me consolaré con la sentencia del sabio que dice que nadie se escapó de detractores en sus obras (S. 78).

Devotion meint hier keine verinnerlichte Form der Religiösität im Sinne der devotio moderna, sondern das Ritual einer bedingungslosen Subjektion unter die Autorität der kirchlichen Institution, ein Ritualglaube, der zur Bedingung wird, um dann erzählerisch ganz offen weltliche Schaulust ausleben zu können. Völlig unmetaphorisch zeigt sich diese Schaulust in einer ganzen Reihe von voyeuristischen Dispositiven, die hier nur durch einen ihrer 〈Höhepunkte〉 belegt werden soll: Auf dem Wege des Pilgers von Riego del Camino nach Moreruela erzählt ein Kleriker die Geschichte der falschen «Heiligen〉 Magdalena vom Kreuze, die auf einem im 16. Jahrhundert berühmt gewordenen historischen Fall beruht ${ }^{24}$. Kulminations- und Wendepunkt dieser Geschichte ist der neugierige Blick («con curiosidad»), den eine Mitschwester durch ein selbstangebrachtes Loch aus der Nebenzelle wirft, um das fromme Verhalten der Heiligen beobachten zu können, wodurch sie - selbstverständlich voller Entsetzen — zur Zeugin eines unzüchtigen Treibens wird:

¡quien diria señores, lo que allí vido! ¿cómo era posible pensar tan gran maldad? ¿cómo era creible una cosa tan monstruosa y extraordinaria, que á la misma que lo estaba viendo se le erizó el cabello y no lo queria creer, puesto que vió joh asombro! patente y claramente que la Madalena de la Cruz, que no comia jamás carne, tenia en su celda una messa bien bastecida de gallinas, capones, perdices,

23 Die doppelte Motiviertheit der Erzählung zeigt sich formal daher in den zwei «tipos de discurso» des Erzählers, die Victoria Campo unterscheidet: «la descripción de los lugares» und «el relato de las historias de los personajes que se encuentra»; vgl. Victoria Campo, «Acerca del itinerario» (Anm. 22), S. 200. Die Beschreibung der «heiligen Orte» verläuft dabei nicht realistisch-empiriebezogen, sondern topisch-wissensorientiert, als Auflistung dessen, was jeder halbwegs gebildete Zeitgenosse über diese Orte selbst wissen oder lesen konnte. Dem topischen Charakter der beschriebenen Orte entspricht die abstrakte Leere des geographischen Raumes, der «vide déscriptif», auf den Françoise Crémoux bei der Suche nach möglichen realistischen Landschaftsdarstellungen oder Beschreibungen eines ortsverbindenden und damit raumkonstituierenden Weges trifft.

24 Vgl. die Dokumentation des Falles bei Jesús Imirizaldu, Monjas y beatas embaucadoras, Madrid: Nacional, 1978, S. 31-62. 
francolines, pavos, faisanes, y muchas piernas de carnero, y cazuelas, y pechugas y tortas de manjar blanco [...] y lo que más la espantaba era que la gran castidad y recogimiento de la Madalena de la Cruz estaba profanada allí, holgandose y abrazandose con un hombre negro, feo, espantable, y que tenia acceso carnal y torpe el sucubo dañado con Madalena de la Cruz [...] (S. 340).

Wie zu erwarten, endet die Geschichte in der reuigen Bekehrung der Sünderin, ihrem öffentlichen Abschwören vor dem Inquisitionstribunal und späterem devoten Leben «con grande ejemplo y penitencia» (S. 347), ein minimalistischer didaktischer Schluss, der die zuvor lang und intensiv genossenen Schaulust im letzten Moment einer topischen exemplarischen Funktion unterordnet $^{25}$.

Der Peregrino curioso zeugt in seiner bemerkenswert offensiven Insistenz auf dem Recht, neugierig und schaulustig sein zu dürfen, insgesamt von der Verweltlichung des religiösen Pilgerrituals, eine Verweltlichung, die aus der Sicht der spirituell-evangelischen peregrinatio-Konzeption zwar einer Profanierung gleichkommen muss, die aber zugleich mit einer «Sakralisierung〉 der iberischen Halbinsel zum Raum einer geheiligten Tradition einhergeht und daher durchaus kein Problem für die spanischen Zensoren darstellte, die nichts Häretisches im Text entdecken konnten. Die Orthodoxie, die der Protagonist mit ständiger Respektsbezeugung vor den kirchlichen und weltlichen Autoritäten und Elementen der Volksfrömmigkeit an den Tag legt, entspricht dem Status seines Standes und dem Selbstverständnis eines Autors, der sich als Teil der konservativen katholischen Führungselite begriff, wie seine politischen Ratschläge zur Krönung Philipps III. und seine Intervention gegen das von Pérez de Herrera eingeleitete Projekt zur Reformierung des Bettlerwesens zeigen ${ }^{26}$. Diese Orthodoxie ist frei von spirituellen Intentionen und erklärt sich in erster Linie sozialpragmatisch. Dass der Peregrino curioso nie gedruckt wurde, liegt daher auch sicher nicht an der möglichen Anstößigkeit seiner kuriosen Weltlichkeit, sondern wahrscheinlich nur an der fehlenden Lust des Autors, die angekündigten zwanzig Bücher auch wirklich zu vollenden.

25 Ein weiteres voyeuristisches Dispositiv stellt z. B. das vermeintliche agujero dar, durch das der Körper des Heiligen Santiago nach Ansicht einiger Pilger erblickt werden könne (vgl. S. $383)$.

26 Vgl. Pérez y Martín, Cartas del «Doncel de Xérica» (Anm. 14). Es handelt sich um die Carta al rey Don Felipe de Austria, Tercero de este nombre, S. 243-252, sowie um die Apuntamientos contra la Premática de los pobres, S. 253-361. Zur zeitgenössischen Debatte um Pérez de Herreras Amparo de Pobres (1598) vgl. die Ausführungen von Michel Cavillac in der Einleitung zu der von ihm besorgten Textausgabe: Cristóbal Pérez de Herrera, Amparo de Pobres, hrsg. v. Michel Cavillac, Madrid: Espasa-Calpe, 1975, insbes. S. CXXIX-CLXXIX. 


\section{Liebespilgerschaften inter fanum et profanum: Jerónimo de Contreras' Selva de aventuras}

Villalba y Estañas Text basierte auf einem Verständnis von peregrinatio im engen, rituellen Sinne, als Reise ad loca sancta ${ }^{27}$. Typisch für die literarischen Funktionalisierungen der peregrinatio im späten 16. Jahrhundert ist aber auch und gerade in Spanien die metaphorische Ausweitung und eine allegorische Figurierung des Pilgerschaftskonzeptes über die Gattungsgrenzen hinweg. Die literarische Pilgerschaft muss damit auch formell nicht mehr durch Orte des Heiligen führen oder von ihnen strukturiert sein. Unabhängig von der jeweiligen konkreten Funktionalisierung im Einzelfall ist dieser Metaphorisierungsprozess, den vor allem Jürgen Hahn in einer materialreichen Studie ausführlich dokumentiert hat ${ }^{28}$, an sich selbst wohl der klarste Beweis für die frühneuzeitliche Verweltlichung des Pilgergedankens. Einen bedeutenden Strang bildet dabei die peregrinatio amoris, die zunächst in der italienischen Renaissance sowohl in der petrarkistischen Lyrik als auch in novellistischromanesken Prosaformen kultiviert und ausdifferenziert wurde ${ }^{29}$. Unter den Bedingungen der spanischen Gegenreformation konnte dieses literarische «Erbe» nicht problemfrei angetreten werden, wie sich exemplarisch an Jerónimo de Contreras' Selva de aventuras zeigen lässt ${ }^{30}$. Dieser Text, der im ausgehenden 16. Jahrhundert bemerkenswerten Erfolg hatte ${ }^{31}$, bildet in der gattungsgeschichtlichen Entwicklungslinie die entscheidende Scharnierstelle

27 Dem Text ging eine reale Pilgerschaftsreise voraus, die Villalba zwischen 1573 und 1576 unternahm und die auch durch textexterne Dokumente belegt ist. Vgl. Pérez y Martín, Cartas del «Doncel de Xérica» (Anm. 14), S. 51-67.

28 Jürgen Hahn, The Origins of the Baroque Concept of Peregrinatio, Chapel Hill: University of North Carolina Press, 1973.

29 Zur Traditionslinie der Liebespilgerschaft vgl. ebd., Kap. 2, S. 63-113, sowie die Studien von Antonio Vilanova: «El peregrino andante en el Persiles de Cervantes», in: Boletín de la Real Academia de buenas letras de Barcelona 22 (1949), S. 97-159; «El peregrino de amor en las Soledades de Góngora», in: Estudios dedicados a Ramón Menéndez Pidal, Madrid: CSIC, 1952, Bd. 3, S. 421-460; «Nuevas notas sobre el tema del peregrino de amor», in: Studia Hispanica in honorem R. Lapesa, Madrid: Gredos, 1972, Bd. 3, S. 563-570.

30 Zitiert wird im Folgenden nach der mit einer sehr informativen Einleitung versehen Edition von Miguel Á. Teijeiro Fuentes, die die beiden Fassungen von 1565 und 1583 enthält: Jerónimo de Contreras, Selva de aventuras (1565-1583), hrsg. v. Miguel Á. Teijeiro Fuentes, Zaragoza: Institución Fernando el Católico, 1991.

31 Von den beiden verschiedenen Fassungen der Selva de aventuras, von denen noch zu sprechen sein wird, sind zwischen 1565 und 1625 insgesamt 16 verschiedene Editionen nachweisbar, zu denen noch die Ausgaben der französischen Übersetzung (Lyon 1580, Paris 1587) hinzugerechnet werden können. Eine bibliographische Übersicht der existierenden und vermuteten Ausgaben inklusive der Übersetzungen leistet Maria Letizia Tubini, «Per una bibliografia della Selva de aventuras di Jerónimo de Contreras», in: La Bibliofilia 77 (1975), S. 127-154. Von der Beliebtheit des Buches zeugt auch die Tatsache, dass es nach Amerika exportiert wurde. Belegt ist der Export von sechs Exemplaren der Selva im Rahmen einer Lieferung von 350 Büchern nach Mexiko im Jahre 1576 sowie ein Export nach Manila im Jahr 1583, zusammen mit Heliodors Teágenes y Cariclea (vgl. Selva de aventuras, Einleitung, S. XIII), was nicht zwangsläufig Indiz für eine generische Relation sein muss, aber zumindest für ein gemeinsames Lesepublikum spricht. 
zwischen der italienischen Renaissance einerseits, konkret Boccaccios Filocolo bzw. den darin enthaltenen Questioni d'amore ${ }^{32}$ und Jacopo Caviceos $I l$ libro del Peregrino ${ }^{33}$, und den großen spanischen Liebespilgerromanen von Lope de Vega und Cervantes auf der anderen Seite ${ }^{34}$. Die Einschätzung der Rolle dieses Textes im Transformationsprozess zwischen renacentistischer und barocker Liebespilgerschaft ist durch eine entscheidendes Faktum erschwert: die merkwürdige Verdoppelung des Textes in zwei Fassungen, durch die zwei unterschiedliche Liebeskonzeptionen in Konkurrenz zueinander treten. Im ganz materiellen Sinne ist die Selva de aventuras gedoppelt, denn neben der Version in sieben Büchern, die erstmals 1565 erschien, lag seit 1583 auch eine Version in neun Büchern vor. Beide Versionen wurden parallel veröffentlicht und erlebten mehrere Auflagen im 16. und Anfang des 17. Jahrhunderts, bis das Werk schließlich auch in den spanischen Index aufgenommen wurde, nachdem es bereits 1581 in Portugal indiziert worden war $^{35}$. Die zweite Version unterscheidet sich bis kurz vor Schluss nur in minimalen Kleinigkeiten von der ersten, bietet dann aber einen ganz anderen Ausgang der Geschichte. In der ersten Fassung wird erzählt wie sich der sevillanische Caballero Luzmán in Arbolea verliebt, die er schon seit früher Jugend kennt und verehrt, und ihr die Heirat anträgt, von dieser aber abgewiesen wird, weil sie «común deseo y apetito sensual» ablehnt (S. 11) und ausschließlich Gott als dem «verdadero amor, que jamás cansa ni tiene fin», angehören will.

32 Diego López de Ayalas Übersetzung der «Quistioni d'amore» erschien erstmals 1541 (Sevilla: Andrés de Burgos) unter dem Titel Laberinto de amor und dann in zweiter Auflage 1546. Mit der dritten Auflage wurde der Titel zu Trece cuestiones muy graciosas sacadas del Philoculo, der auch in der vierten und fünften Auflage beibehalten wurde (Toledo: Juan de Ayala, 1546 u. 1549). Die Editionsgeschichte lässt sich über die Daten in der Datenbank der Biblioteca Telemática de Traducciones Españolas de la literatura italiana (Biteli) im Rahmen des «Proyecto Boscán» leicht erschließen (URL: http://www.ub.es/boscan/).

33 Caviceos Werk erschien unter dem Titel Historia nuevamente hecha de los honestos amores que vn cauallero llamado Peregrino tuuo con vna dama llamada Ginebra wohl erstmals gegen 1520 (Sevilla: Jacobo Cromberger), wobei sich der Übersetzer Hernando Díaz als Autor des Werkes ausgab. Zur spanischen Übersetzung des Werkes vgl. Clive Griffin, «Giacomo Caviceo's Libro del Peregrino: the Fate of an Italian Wanderer in Spain», in: Anna Laura Lepschy/John Took/Dennis E. Rhodes (Hrsg.), Book Production and Letters in the Western European Renaissance. Essays in Honour of Conor Fahy, London: The Modern Humanities Research Association, 1986, S. 132-146, sowie Javier González Rovira, «El Libro del Peregrino de Giacomo Caviceo y la traducción de Hernando Díaz», in: Studi ispanici, Pisa, 1997, S. 51-60. Als Textgrundlage wird im folgenden die Edition aus dem Jahr 1548 herangezogen, die vermutlich die dritte Auflage darstellt.

34 Antonio Vilanova, «El peregrino andante» (Anm. 29), S. 105-107, nennt diese Filiationslinie, geht aber nicht weiter auf die dabei stattfinden Transformationsprozesse ein. Die gattungsgeschichtlich orientierten Studien von González Rovira, La novela bizantina de la Edad de Oro, Madrid: Gredos, 1996, S. 182-201, und Christine Marguet, Le roman d'aventures et d'amour en Espagne XVIe-XVIIe siècles. L'utile et l'agréable, Paris: Harmattan, 2004, gehen zwar auf die Selva de aventuras näher ein, bewegen sich jedoch im engen nationalphilologischen Rahmen und berücksichtigen die italienischen Texte bzw. deren Übersetzungen ins Spanische als mögliche Hypotexte gar nicht.

35 Vgl. Márquez, Literatura e inquisición en España (Anm. 11), S. 183 f., sowie Alcalá, Literatura y ciencia ante la inquisición española (Anm. 11), S. 110. 
Worauf Luzmán sich, als Pilger verkleidet, auf eine Rundreise nach Italien begibt, wo er unterschiedliche Begegnungen mit meist unglücklichen Liebenden hat, die ihm ihre jeweilige Geschichte erzählen. Obwohl er dadurch immer wieder an sein eigenes Liebesleid erinnert wird, bleibt er in seinem Verhalten vernünftig und gelassen und kann unterwegs auch häufiger touristischen Interessen nachgehen. Bei seiner Rückkehr nach Sevilla muss er dann erfahren, dass Arbolea inzwischen in ein Kloster eingetreten ist, ein Beispiel, dem er selbst folgt, indem er zum Einsiedler wird und sich ebenfalls jener asketisch-frommen Liebe zu Gott hingibt, die ihm als das absolute Gesetz seiner señora selbst zum Gesetz wird.

Contreras' erste Schlusslösung wurde unter anderem als der Versuch zur Schaffung einer novela sentimental «a lo divino» interpretiert ${ }^{36}$ und lässt sich in der Tat als eine Christianisierung der Liebespilgerschaft verstehen, wenn man sie vor der Folie von Caviceos bzw. Hernando Díaz' Peregrino y Ginebra liest, einem Text, der stark von mythologisch-paganen Elementen durchsetzt ist und eine deutliche Tendenz zur Profanierung aufweist - am deutlichsten in der Szene, in der sich Peregrino im Inneren einer Statue der jungfräulichen Heiligen Katharina versteckt in die Kammer seiner Liebsten einschmuggelt ${ }^{37}$. Peregrinos Liebespilgerschaft hat am Ende Erfolg, und er ehelicht und begattet Ginebra, ein Triumph, der ihn zu Dank an Jupiter bewegt und der hyperbolisch als eine Leistung gefeiert wird, welche die Heldentaten der Römer in den Schatten zu stellen vermag ${ }^{38}$. Angesichts solcher schwankhaft-profanierenden Züge ist es kaum verwunderlich, dass Peregrino y Ginebra von Anfang an von der spanischen Zensur erfasst wurde ${ }^{39}$. Wenn vor diesem Hintergrund

36 «Nos hallamos, pues, ante una novela sentimental, pero vuelta a lo divino, en la que la mediación - superioridad del amor divino sobre el humano - impide la unión de los enamorados en la tierra para realizarla en un plano superior» (Armando Durán, Estructura y técnicas de la novela sentimental y caballeresca, Madrid: Gredos, 1973, S. 170).

37 Libro de los honestos amores de Peregrino y Ginebra, Sevilla: Jacome Cromberger, 1548, Kap. 46: «Peregrino fabrico vna ymagen de Sancta Catalina: de dentro dela cual se hizo lleuar a casa de Ginebra». Peregrino lässt sich dabei beim Bau seiner «artificiosa machina» vom antiken Vorbild des trojanischen Pferdes inspirieren: «la qual con aquel engaño feneciesse mis ansias como el simulachro de los griegos dedicado ala Palas. Fengi por la passada dolencia auer seruido con vna ymagen ala virgen sancta Catalina: la qual era de tanto altor i profundidad que facilmente enel concauo vientre podia assentado reposar: enel centro estaua vna puerta con tanto artificio fabricada: que los ojos del cieruo no la deuisavan: puesta sobre vna adornada carreta. Con aquella muestra de tormentos que para eternal bienauenturança ygualmente conel cuerpo la anima sostiene» (fol. liii $\left.\mathrm{v}^{\circ}\right)$.

38 Vgl. Kap. 152: «Peregrino da gracias a Jupiter y ofrece las armas al templo», wo sich der Protagonist zu folgendem Dankgebet veranlasst sieht: «O Gran Jupiter: cuya virtud al vniverso rige: a tu sancto templo las vencedoras armas ofrezco: pues de tanta pelea ya tengo el triumpho. Aquesta es aquella combatida prouincia que a su vencedor glorioso i immortal le buelue» (fol. cxiiii $\mathrm{v}^{\circ}$ ). Peregrinos Liebestriumph wird allerdings nicht von langer Dauer sein, da seine Gattin schon bald nach der Ehelichung verstirbt.

39 Als eines der wenigen Werke der Profanliteratur wurde Peregrino y Ginebra bereits in den Index von Valdés (1559) aufgenommen. Vgl. Fr. Heinrich Reusch (Hrsg.), Die Indices librorum prohibitorum des sechzehnten Jahrhunderts, Tübingen: Literarischer Verein in Stuttgart, 1886, S. 238. 
Contreras' Fassung von 1565 als eine asketische Resakralisierung der Liebespilgerschaft erscheint, ist es umso rätselhafter, warum diese Option in der zwei Jahrzehnte später in Alcalá de Henares erscheinenden neunbändigen Selva verworfen und der Schluss verändert wurde ${ }^{40}$ : Die in der ersten Fassung völlig passive Arbolea wird zur Erreichung dieser neuen Schlusswendung aktiviert. Durch ihre eigene Reise, die sie nach dem Tode ihres Vaters unternimmt, löst sie eine zweite Liebespilgerschaft Luzmáns nach dessen Rückkehr nach Sevilla aus, was schließlich zum Zusammentreffen in Portugal und zum neuen happy end führt. Die platonisch-freundschaftliche Verbindung, die Luzmán und Arbolea im Namen Gottes eingegangen waren, ist damit entsublimiert, und beide werden zu profanen Eheleuten, die sich auch sexuell vereinen, was im Text direkt angesprochen wird ${ }^{41}$, wobei die Darstellung den Vollzug eines zuvor durch das Heiratsversprechen geschlossenen und anschließend vor der christlichen Gemeinde bestätigten Sakramentes betont und nicht die fleischliche Lust, die bei Caviceo triumphierte. Die Reichhaltigkeit der Nachkommenschaft und der soziale Status der neuen Familie unterstreichen noch einmal die moralische Legitimität dieser weltlichen Verbindung:

Era Luzmán a esta sazón de treinta y un años, y Arbolea de veintiocho, y vivieron después de casados cincuenta años, tuvieron tres hijos y dos hijas, que el menor de los hijos se llamó como su padre, y fue de los nobles y generosos caballeros de su tiempo. Y aquí da fin el noveno libro y último desta Selva de aventuras a honra y gloria de Dios (S. 175).

Beide Schlüsse lassen sich im Vergleich zu Caviceos Pilgerschaftsroman als Versuche einer Resakralisierung verstehen, wobei sie auf jeweils zwei unterschiedliche Formen der im Verständnis der katholischen Morallehre einzig

40 Zur Problematik des doppelten Schlusses vgl. insbesondere Ruth H. Kossof, die den Wechsel aus der Attraktion des byzantinischen Romans als «neuem» Gattungsmodell zu erklären versucht: «Las dos versiones de la Selva de aventuras de Jerónimo de Conteras», in: Actas del Sexto Congreso Internacional de Hispanistas, Toronto: Department of Spanish and Portuguese, University of Toronto, 1980, S. 435-439. Barbara N. Davis sieht im Wechsel zum byzantinischen Modell einen kuturhistorisch symptomatischen «move away from the medieval conceits of courtly love towards the modern idealization of conjugal love»; vgl. «Love and/or marriage: the surprising revision of Jerónimo de Contreras's Selva de aventuras», in: Hispanic Review 50 (1982), S. 173-199, hier S. 194. Ähnlich schließlich González Rovira, der glaubt «que las modificaciones de Contreras obedecen a un factor literario: la lectura de Heliodoro»; vgl. La novela bizantina (Anm. 34), S. 186. In diesen Erklärungsversuchen wird jedoch von einem Modellwechsel ausgegangen, wo de facto die Koexistenz zweier zumindest rezeptionsgeschichtlich gleichwertiger und vom Publikum offenbar ebenso geschätzter Fassungen vorliegt. Das eigentliche Problem, die Verdoppelung des Textes, bleibt damit ungelöst.

41 «Quedaron Luzmán con su señora Arbolea acostados en una rica cama, que, cuando allí se vieron, no se podría contar lo que los dos sintieron y las palabras amorosas que pasaron, contanto [sic] el uno al otro sus trabajos. Y gozándose en lo demás que sus corazones y voluntades deseaban, ataron el verdadero nudo del santo matrimonio en una voluntad unidos, porque verdaderamente se amaron mucho» (S. 175). González Rovira, «El Libro del Peregrino de Gioacomo Caviceo» (Anm. 33), übergeht die profanierend-schwankhaften Seiten des Werkes komplett. Nur so kann er in diesem Text einen «claro precedente de la visión desengañada de algunas de las novelas bizantinas españolas» ausmachen. 
legitimen Liebesformen abzielen: asketische Enthaltsamkeit und ausschließliche Konzentration auf die Liebe zu Gott einerseits, sakramental geheiligte und durch den Reproduktionszweck legitimierte weltliche Liebe andererseits. Beide Varianten schließen sich dabei nicht logisch oder systematisch aus, denn sie werden vielmehr bereits im Rahmen der ersten Selva als legitime Möglichkeiten der Liebe diskutiert und lassen sich daher als im Prinzip ergänzende Positionen in einem 〈Spiel〉 mit der christlichen Liebe verstehen, das sich in einem Transformationsprozess aus den höfischen kasuistischen Liebesspielen ${ }^{42}$ über die Zwischenstufe der renascentistischen Liebesdialoge ${ }^{43}$ entwickelt und dabei mit neoplatonischem Gedankengut verbunden hat ${ }^{44}$. Das oft als Streit beginnende, aber meist friedlich endende und sich immer im Rahmen gepflegter Gesellschaftsformen haltende diskursive und allegorisch-theatralische Durchspielen konkurrierender Liebeskonzeptionen stellt in der ersten Version der Selva jedenfalls das zentrale Strukturprinzip dar ${ }^{45}$. Die Italienreise Luzmáns hat dabei nichts von einem Abenteuer im aktionistischen Sinne ${ }^{46}$, sondern ist aventure vielmehr im Sinne einer auf die

42 Zur Tradition der höfischen Liebeskasuistik ausgehend vom provenzalischen joc partit über Andreas Cappelanus De Amore (um 1186) bis zu Martials Arrêts d'Amour (um 1460) vgl. die Zusammenfassung bei Karin Becker, Amors Urteilssprüche. Recht und Liebe in der französischen Literatur, Bonn: Romanistischer Verlag, 1991, S. 214-318.

43 Als besonders paradigmatischer Text können dabei Leone Ebreos Dialoghi d'amore gelten, die erstmals 1535 in Rom erschienen. Die Erstauflage der spanischen Übersetzung durch Guedella Yahia wurde 1568 in Venedig verlegt.

44 Boccaccios Filocolo, der in der Forschung lange Zeit lediglich als ein schwaches Jugendwerk galt und nur als Vorläufer des Decamerone von Interesse schien, dürfte in diesem Transformationsprozess, der erst ansatzweise aufgearbeitet ist, eine entscheidende Stellung innehaben. Der Reigen der Liebesdialoge, der dabei unter Regentschaft Fiammettas in einer Art Auszeit der Haupthandlung veranstaltet wird, ist jedenfalls noch deutlich nach dem Modell der höfischen Liebeskasuistik modelliert, wobei die dilemmatischen Streitfragen jedoch formal zu einer Entscheidung kommen und im Rahmen der Haupthandlung eine neue Funktion gewinnen. Paolo Cherchi hat auf die Rolle der kasuistischen Liebesdebatten als «suasoria por Florio» hingewiesen, «un modo di confortarlo a prosegire la sua vocazione amorosa sulle linee della discretio, della liberalitas, della magnanimitas, cioè secondo gli insegnamenti delle virtù cortesi» («Sulle quistioni d'amore nel Filocolo», in: P. C., Andrea Cappellano, i trovatori e altri temi romanzi, Roma: Bulzoni, 1979, S. 210-217, hier S. 217). Victoria Kirkham, «Reckoning with Boccaccio's Questioni d'amore», in: Modern Language Notes 89 (1974), S. 47-59, geht von einer ähnlich entscheidenden Umfunktionierung der höfischen Liebeskasuistik aus, die in den Rahmen einer allegorischen weltlichen Liebespilgerschaft eingelassen und damit einem neuen Ideal christlicher Liebe unterstellt werde.

45 González Rovira spricht zu Recht von einer «casuística amorosa con distintas modulaciones desde una perspectiva cristiana que las engloba a todas»; vgl. La novela bizantina (Anm. 34) S. 192. Die allegorisch-theatralische Darstellungsform, die Contreras dabei wählt (vgl. z. B. bereits im ersten Buch den Auftritt der Republik Venedig als Dame, der die Heirat angetragen worden ist und die sich nun sich für Libertad oder Sujeción zu entscheiden hat, S. 16-21), wird dann Lope de Vega aufgreifen, indem er autos sacramentales in die Struktur seiner Prosaerzählung integriert.

46 Dies wurde in der Forschung schon häufig konstatiert, so etwa von Armado Durán, der vom versprochenen Abenteuer gar nichts entdecken kann: «se limita a estar físicamente presente en el título de la novela y nada más - en ninguno de los siete libros de la Selva puede 
Zukunft gerichteten Erwartungsspannung, als Frage nach dem Ende eines Spieles, das nicht zufällig im Ambiente der italienischen Fürstenhöfe ausgetragen wird und damit noch als renascentistisches Erbe erkennbar bleibt, auch wenn es nun unzweideutig dem Gesetz Gottes unterstellt und so christlich gewendet worden ist ${ }^{47}$. Anders als im Falle des Spiels mit der höfischen Liebe, das Sebastian Neumeister seinerzeit als ein in sich geschlossenes artifizielles System interpretieren konnte ${ }^{48}$, findet Contreras' Spiel mit der christlichen

vislumbrarse el más leve indicio de una aventura, bien sea caballeresca, bien sea bizantina»; vgl. Estructura y técnicas de la novela (Anm. 36) S. 168. Ruth H. Kossoff, "Las dos versiones de la Selva» (Anm. 40), sieht den Protagonisten, der selbst sicher kein Abenteurer ist, dagegen in seiner Rolle als Beobachter und Berichterstatter durchaus als den Vermittler von Abenteuern: «las 〈aventuras» de este libro son las de los conocidos y amigos de Luzmán» (S. 134).

47 Dass das «Gesetz der geregelten Offenheit», das nach Sebastian Neumeister die Struktur des altprovenzalischen Partimen und der daraus abgeleiteten Formen der Liebeskasuistik bestimmt (vgl. Das Spiel mit der höfischen Liebe, München: Fink, 1969, S. 35, 115, 164), nunmehr christlich bestimmt ist, wird vor allem durch das allegorische Schauspiel deutlich, das in der Residenz des Kardinals Juliano in Rom veranstaltet wird und zeigt, wie AMOR DIVINO, der von den sieben Kardinalstugenden umgeben ist, über den AMOR HUMANO, dem die sieben Todsünden beigesellt sind, triumphiert (S. 107-115). Eine derartige Christianisierung der Liebeskasuistik auf dem Wege der Allegorisierung ließe sich zwar schon für Boccaccio behaupten, wenn man der These von Victoria Kirkham folgt, kann aber keineswegs als typischer und dominanter Zug der italienischen Renaissance gelten, die insgesamt in ihrem Versuch einer Vermittlung von heidnischer Antike und christlichem Denken sehr ambivalent blieb. Caviceos Peregrino ist das beste Beispiel dafür, dass im italienischen Humanismus der pagane Mythos nicht einfach in den Dienst des christlichen Gottes gestellt wurde, sondern durchaus lustvoll als Mythos genossen werden konnte - auch und gerade durch einen Kleriker. Zur Biographie Caviceos vgl. Lorena Simona, Giacomo Caviceo. Uomo di chiesa, d'armi e di lettere, Frankfurt a. M. Lang, 1974.

48 Die Beziehung von höfischer und christlicher Liebeskonzeption, die im Aufeinandertreffen der «ars honeste amandi» in den ersten beiden Büchern von Capellanus' De amore mit der «reprobatio amoris» im dritten Buch zu einem Werk zusammengespannt sind, erklärt Neumeister als einen systemischen Gegensatz: Die Zusammenstellung von Lob und Tadel der höfischen Liebe bedeute keine «Koexistenz zweier sich ergänzender Ordnungen, auch nicht die Konzession an eine erst hundert Jahre später wach werdende Zensur. Sie ist vielmehr das Ergebnis jenes Ganzheitsanspruches, den beide Systeme, das christliche und das höfische, an den Menschen stellen, und der eine Versöhnung, eine Halbierung der Ansprüche ausschließt» (S. 106). Was hier als systemischer Gegensatz formuliert ist, versuchte Hans Ulrich Gumbrecht Anfang der 80er Jahre auf der Basis der Luhmannschen Systemtheorie als eine «asymmetrische Negation» genauer zu bestimmen: «Literarische Gegenwelten, Karnevalskultur und die Epochenschwelle vom Spätmittelalter zur Renaissance», in: H. U. G. (Hrsg.), Literatur in der Gesellschaft des Spätmittelalters, Heidelberg: Winter, 1980 (Begleitreihe zum Grundriss der romanischen Literaturen des Mittelalters, 1), S. 95-144, besonders S. 107-111. Auch diesem Versuch wurde, wie zuvor schon der These Neumeisters, zum Teil heftig widersprochen. Der Disput zwischen Gumbrecht und Rüdiger Schnell, der auf der Höhe der Forschung vor inzwischen gut 20 Jahren ausgetragen wurde, scheint mir die auch heute noch grundsätzlich gültigen Fragen aufgeworfen zu haben. Vgl. dazu Rüdiger Schnell, «Kirche, Hof und Liebe. Zum Freiraum mittelalterlicher Dichtung», in: Ernstpeter Ruhe/Rudolf Behrens (Hrsg.), Mittelalterbilder aus neuer Perspektive. Diskussionsanstöße zu «amour courtois», Subjektivität in der Dichtung und Strategien des Erzählens, München: Fink, 1985, S. 75-108, sowie die Replik Gumbrechts, ebd., S. 112-118. 
Liebe aber im Rahmen einer Zensur statt, die den Spielraum der Möglichkeiten aktiv zu lenken versuchte und direkt darauf einwirkte. Die in der Forschung geäußerte Vermutung, dass die zweite Fassung sich aus dem Eingreifen der Zensur erkläre ${ }^{49}$, ist angesichts des Lizenzdatums der Edition von Alcalá, 1578, zwar sicher ausgeschlossen. Allerdings könnte die Erweiterung der ersten Fassung trotzdem eine Art vorbeugende Maßnahme im Vorfeld der Bildung des Index von Quiroga dargestellt haben ${ }^{50}$. Auffällig ist ja immerhin, dass Luzmáns christliche Gesinnung nunmehr konfessionell präzisiert wird: aus dem allgemeinen «caballero cristiano» der ersten Fassung (145) ist ein «católico caballero» (165) geworden, und der Eremit Valerín gibt seinen Segen zur neuen Verbindung aus «cristianas y católicas razones» (173). Diese Spezifizierung sowie die Relativierung der höfischen Kultur Italiens durch die zweite Ausfahrt, die geographisch ganz im Rahmen der iberischen Halbinsel bleibt und sich dabei verstärkt Elementen der zu dieser Zeit im Aufstieg begriffenen und als moralisch unbedenkliche Unterhaltungsliteratur geltende novela bizantina bedient, weist bereits auf den «patriotischen» Pilger Lope de Vegas voraus ${ }^{51}$. Den im Vergleich zur römisch-päpstlichen Zensur gegenüber der weltlichen Literatur zunächst recht liberalen spanischen Zensurbehörden scheinen solche Oberflächensignale katholischer Gesinnung fürs erste ausgereicht zu haben.

Die Gründe für die spätere Zensur der beiden Selvas, die zunächst von Zapata in den Index librorum expurgatorum und später auch in den der librorum prohibitorum aufgenommen wurden, wird man wohl nicht an inhaltlichen Einzelheiten festmachen können, die als blasphemisch oder unorthodox bewertet werden könnten. Immerhin bescheinigte Menendez y Pelayo als ausgewiesener Kenner der spanischen Orthodoxie dem Buch «gravedad y decoro» und gestand ein, das Vorgehen der Zensoren nicht zu verstehen: «a la verdad, no se explica que el Santo Oficio, tan indulgente o indiferente con este género de literatura, hiciese la rara excepción de llevar Luzmán y Arbolea al Indice expurgatorio» ${ }^{52}$. Am wahrscheinlichsten scheint mir als Motiv der Zensoren der strukturelle Zusammenhang des Textes mit der Tradition der höfischen Liebeskasuistik bzw. den Liebesdialogen der Renaissance, die im

49 Juan Bautista Avalle-Arce etwa glaubte, dass gerade die spiritualisierende Absicht der ersten Fassung, «los transportes espirituales», ein Problem dargestellt haben könnte (vgl. die Einleitung zu seiner Ausgabe von Lope de Vegas Peregrino en su patria, Madrid: Castalia 1973, S. 28), geht dabei jedoch von falschen Daten aus. Die Diskussion einer Änderung aus Zensurgründen fasst González Rovira, La novela bizantina (Anm. 34) S. 184-187, zusammen.

50 Das Zirkulieren von pareceres im Vorfeld des Index zeigt, dass die Aufstellung der Liste einen längerfristigen Prozess der Normenbildung darstellte, und es ist anzunehmen, dass die meisten zeitgenössischen Autoren, aus deren Reihen ja auch entsprechende Gutachter stammten, davon wenigstens gerüchteweise Kenntnis hatten.

51 González Rovira bezeichnet den neue geographische Raum der zweiten Fassung der Selva als «un paso para la nacionalización del género propiciada por Lope de Vega»; vgl. La novela bizantina (Anm. 34), S. 200.

52 Menéndez y Pelayo, Orígenes de la novela (Anm. 13) Bd. 2, S. 87. 
ersten Drittel des 17. Jahrhunderts (seit dem Index von Sandoval 1612, vor allem aber seit Zapata 1632) systematisch unterdrückt wurde. Mit der Liebe sollte offensichtlich gar kein Spiel mehr getrieben werden, auch dann nicht, wenn es sich im Rahmen christlich-katholischer Werte hielt ${ }^{53}$. Für die literarische Funktionalisierung der Liebespilgerschaft bedeutete diese Auflösung der Renaissancetradition freilich kein Ende. Sie hatte mit dem «griechischen» Roman schon längst eine neue Prosaform gefunden, in der Affekte weiter in Fiktionen verwandelt und dabei in Bewegung gehalten werden konnten.

\section{Die ambivalente Erfahrung der Fremde: Fernão Mendes Pintos Peregrinação (1614) als Satire und Hagiographie}

Mit Fernão Mendes Pintos Peregrinação soll nun ein drittes Paradigma der literarischen Funktionalisierung des Pilgerschaftskonzeptes untersucht werden. Anders als im Falle des Peregrino curioso, der sich auf die empirische Ritualpraxis des Pilgerns bezog, und anders als der Pilger der Selva, der als eine auf vorausliegenden Hypotexte verweisende metaphorische Figuration der Affektbewegung Liebe fungierte, umspielt diese Pilgerschaft in der Form einer Reisechronik die Grenze zwischen Fiktion und Empirie selbst ${ }^{54}$. Dass ich diesen Text entgegen den Gepflogenheiten nationalphilologischer Arbeitsteilung in ein auf das frühneuzeitliche Spanien zentriertes Corpus integriere, versteht sich nicht von selbst, ist aber historisch völlig gerechtfertigt, denn sowohl aus produktions- wie aus rezeptionsgeschichtlicher Sicht schrieb sich der Text zunächst in den literarischen Raum des transnational agierenden Habsburgerreiches ein ${ }^{55}$.

53 Die mit dem 17. Jahrhundert einsetzende Verschärfung der Zensur zeigt sich sowohl an Boccaccios Laberinto de Amor, der von Zapata auch in der Originalsprache indiziert wird. Leone Ebreos Dialoghi d'amore, die von Quiroga und Sandoval nur zur Expurgierung vorgeschlagen worden waren, werden mit Zapata gänzlich verboten. Ein ähnlicher Prozess ist auch im Falle von Diego de San Pedros Cárcel de amor zu beobachten, der auch erst seit Zapata verboten wird. Offenbar waren die Zensoren des neuen Jahrhunderts nicht mehr bereit, die feinen Unterschiede vorzunehmen, auf denen der Gutachter für den Index von Quiroga noch insistierte, wenn er innerhalb der «cosas de amores» «tratados [...] escritos con honestidad» (wobei ausdrücklich die Carcel de amor und die Celestina erwähnt werden) von «obras con menos recato y honestidad» unterschied. Vgl. den Abdruck des Textes bei Alcalá, Literatura y ciencia (Anm. 11), S. 76-79, hier S. 78.

54 Pintos Reisebericht steht mit seiner Funktionalisierung des Pilgerschaftskonzeptes dabei in einer umfassenderen spanisch-portugiesischen Traditionslinie, die José M. Herrero Massari, Libros de Viajes de los siglos XVI y XVII en España y Portugal, Madrid: Fundación Universitaria Española, 1999, untersucht hat. Auch für andere Reiseberichte ist das peregrinatio-Konzept dabei titelgebend, so im Falle von José de Acostas Peregrinación de Bartolomé Lorenzo (1586) oder Gobeo de Victorias Naufragio y peregrinación (1610).

55 Der portugiesischen Erstausgabe von 1614, die Philipp III. gewidmet war, folgte die spanische Übersetzung durch Francisco Herrera Maldonado 1620, die in den folgenden Jahrzehnten mehrere Neuauflagen erfuhr $(1627,1645,1664$ u. 1666). Zu einer portugiesischen Neuauflage kam es erst wieder 1678, zu einem Zeitpunkt, als bereits Übersetzungen 
Die Aufzeichnungen, die der Autor nach seiner Rückkehr in die Heimat über seine Erlebnisse im fernen Osten zwischen 1537 und 1558, in denen er durch die ganze Weite des damaligen portugiesischen Kolonialgebietes gereist war $^{56}$, angefertigt hatte, blieben zunächst längere Zeit eine Privatangelegenheit, obwohl Pinto selbst offensichtlich starkes Interesse an einer Publikation hatte $^{57}$. Als die Dynastie des Hauses von Aviz nach dem Tod von König Sebastião 1578 ohne Erbfolge blieb und Philipp II. im April 1581 durch die Cortes in Tomar auch die portugiesische Krone überreicht bekam, änderte sich mit der machtpolitischen Konstellation auch die publizistische Ausgangslage. In dieser veränderten Situation kam es Anfang der 1580er Jahre zu Gesprächen zwischen Pinto und den Mitarbeitern des offiziellen Indienchronisten des Jesuitenordens, Pater Giovanni Pietro Maffei, den der neue Herrscher zur Fortführung seiner Dokumentation über das Kolonialreich ermuntert hatte. Offenbar wurden Pintos Aufzeichnungen als ein wissensvermittelndes Dokument im strengen Sinne als zweifelhaft und von geringem Wert eingeschätzt und so kam es trotz dieser Kontakte weder zu einer Veröffentlichung noch zur Verwendung des Textes in den 1588 veröffentlichten offiziellen Historiarum Indicarum Libri XVI. Man muss dahinter keine jesuitische Verschweigungspolitik vermuten, da es ausreichend Gründe gibt, Pintos Lebensbericht als Historiograph mit Skepsis zu behandeln. Schon die autobiographische Erzählform macht ihn zu einer höchst subjektiven, vom Drang zur Selbststilisierung geprägten Informationsquelle, die ihre Fakten ihrerseits oft auch nur aus zweiter Hand bezog, wie vor allem Georg Schurhammer nachgewiesen hat ${ }^{58}$.

ins Französische, Englische, Holländische und Deutsche vorlagen. Die umfangreiche Editionsgeschichte des Textes und seiner Übersetzungen dokumentiert Francisco Leite de Faria, As muitas edições da «Peregrinação» de Fernão Mendes Pinto, Lisboa: Academia Portuguesa da Historia, 1992.

56 Die Reiseroute Pintos lässt sich über die chronologische Inhaltsübersicht erschließen, die Georg Schurhammer bietet: «Fernão Mendes Pinto und seine Peregrinaçãm», in: Gesammelte Studien, Bd. 2: Orientalia, hrsg. v. László Szilas, Lisboa: Centro de Estudios Históricos Ultramarinos, 1963, S. 23-104, hier S. 28-35. Es wurden auch Versuche zu einer geographischen Rekonstruktion unternommen. Vgl. dazu etwa die Karte des Visconde de Lagoa, die 1947 angefertigt wurde und der modernisierenden Edição Comemorativa dos Descobrimentos Portugueses vorangestellt ist (Peregrinação \& Cartas, 2 Bde., Lisboa: Fernando Riberiro de Mello/Edições Afrodite, 1989).

57 Ich halte mich hier an die Daten zur Genese des Textes, die José Manuel Garcia in der Präsentation der Faksimileausgabe der Erstedition der Peregrinação bietet, nach der im Folgenden auch zitiert wird. 1571 sei der Autor danach «numa fase avançada da sua obra» gewesen, «alimentando a esperança de em breve a poder concluir, admitindo mesmo a hipótese de a dedicar a Cosme de Médicis, de quem contaria receber apoio para a edição.» (Peregrinaçam de Fernam Mendez Pinto, Maia: Castoliva, 1995, S. 10).

58 Vgl. Schurhammer, «Fernão Mendes Pinto und seine Peregrinaçam» (Anm. 56). Schurhammers Studie, die erstmals 1926 in der Zeitschrift Asia Major (Nr. 3, S. 71-103 u. S. 194-267) veröffentlicht wurde, bezieht ihr Movens aus der durchaus gläubigen Verehrung des Heiligen Franz Xaver, an dessen Biographie der Gelehrte praktisch lebenslang arbeitete. Als Initialerlebnis soll dabei eine Pilgerreise nach Goa zur Anrufung des Heiligen 
Das Verhältnis der Jesuiten zum Abenteurer Pinto, der 1554 angeblich unter dem Eindruck der Rückführung des Leichnams des Jesuitenmissionars, den er in Japan kennengelernt hatte, in die Gesellschaft eintrat, dann mit Nunes Barreto als Gesandter des Vizekönigs über Malakka und China nach Bungo reiste und dort aber wieder aus der Gesellschaft austrat ${ }^{59}$, war aber nicht immer von solch szientistischer Objektivität geprägt, und Schurhammer schreibt mit seiner positivistischen Dokumentation auch nicht in erster Linie gegen die im Portugiesischen inzwischen sprichwörtlichen «Lügen〉 des Mendes Pinto ${ }^{60}$ an, sondern gegen deren Verwendung zur hagiographischen Legendenbildung, an der die Societas Jesu selbst entscheidend beteiligt gewesen war. Schurhammer bemüht sich um eine wissenschaftliche Trennung von Fakten und Fiktionen, deren Vermischung zu Beginn des 17. Jahrhunderts durchaus erwünscht war, als es im Zuge der Selig- und anschließenden Heiligsprechung Francisco de Jassu y Javiers darum ging, die Wundertätigkeit des Missionars durch möglichst viele Dokumente zu belegen und dabei nicht unbedingt die Glaubwürdigkeit, sondern die publizistische Wirksamkeit der Belege ausschlaggebend war. Es ist jedenfalls kein Zufall, dass der Text genau zu der Zeit publikationswürdig wurde, als die Legendenbildung im vollen Gange war: ein Jahr nach dem Erscheinen der portugiesischen Erstausgabe (1614) wurde der rechte Unterarm des Jesuitenpaters als Reliquie nach Rom überführt, wo er am 25. Oktober 1619 selig- und am 12. März 1622 heilig-

gestanden haben. Schurhammers Glaube mag insofern subkutan als persönlicher Studienantrieb entscheidend gewesen sein, seine Studie ist aber insgesamt vom professionellen Ethos des Wissenschaftlers bestimmt und in ihrer positivistischen Genauigkeit immer noch nicht überholt.

59 Einen knappen Abriss der aus historischen Quellen bezeugten Autobiographie Pintos bietet Schurhammer, ebd., S. 98 f. Eine Sammlung der historischen Quellen liefert Rebecca Catz, Cartas de Fernão Mendes Pinto e outros documentos, Lisboa: Editiorial Presença/ Biblioteca Nacional, 1983, die in ihrer Einleitung auch sehr knapp den Stand der biographischen Forschung zu Pinto resümiert (S. 13-15). Die Tatsache, dass Pinto sein ambivalentes Verhältnis zum Jesuitenorden in der Erzählung unerwähnt lässt, gab immer wieder Anlass zu Spekulationen über mögliche Eingriffe in den Text durch den Herausgeber. «The decision to omit any reference to it [i. e. the decision to become a Jesuit] may not have been made by Mendes Pinto himself but by whoever prepared his manuscript for publication», formuliert etwa Thomas R. Hart, "(Pleasant Harmless Lies». Fernão Mendes Pinto's Peregrination», in: Boletim de Filologia 29 (1984), S. 221-230, hier S. 225.

60 Dabei wurde der Autorname schon von den zeitgenössischen Lesern des Textes in die Nähe von Mentes bzw. Mendax gerückt und zur Bildung eines wortspielhaften Echodialogs genutzt: «- Fernão, mentes? - Minto!». Ein Wortspiel, dessen Erwähnung inzwischen zum festen Topos der Kommentatoren der Peregrinação geworden ist. Das Verhältnis von Fakten und Fiktionen in Pintos Text bildete entsprechend von Anfang an ein Hauptthema der Forschung. Schurhammers Insistieren auf dem unzuverlässigen Charakter des Textes als historischer Quelle stehen Einschätzungen wie die von Herbert A. van Scoy gegenüber, der meint: «From the historical standpoint, then, the Peregrinaçam must be accepted on the whole as the truthful relation of a man of great imagination and enthusiasm. To the average reader, an occasional error in date or distortion of a proper name is irrelevant.»; «Fact and Fiction in Mendez Pinto's Peregrinaçam», in: Hispania 32 (1949), H. 2, S. 158-167, hier S. 166. 
gesprochen wurde. In diesen Zeitraum fällt auch die spanische Übertragung durch Francisco Herrera Maldonado, der in seiner einleitenden, auf den 30. Mai 1618 datierten «Apologia en favor de Fernand Mendez Pinto, y desta Historia Oriental» kein Mittel ungenutzt lässt, den Text zur seriösen Quelle aufzuwerten. Gleich zu Beginn wird Philipp II., «verdaderamente Principe Catolico, Prudente y dignissimo» (fol. I $\left.\mathrm{r}^{\circ}\right)^{61}$ als Akkreditierungsinstanz eingesetzt, da er selbst dem Bericht des Autors in mündlicher Anhörung Glauben geschenkt habe:

passava muchos ratos con oyrle, dando tanto credito a sus verdades, como era
buen testigo el tiempo que gastaua en saberlas: porque a no serlo, no le perdiera en
cosas valdias, y dudosas, patrañas sin sustancia ni orden, quien tan grandemente
detestaua la mentira, y tan bien conocia la verdad (ebd.).

Der Nobilitierung des Autors mit Hilfe der königlichen Autorität folgt die Entautorisierung des Herausgebers des ersten Textes, Francisco de Andrade, der das Original nicht verbessert, sondern nur verschlimmbessert habe. Als dritte und ergänzende Strategie zum Zwecke, dem Text ein Höchstmaß von Glaubwürdigkeit zu verleihen, folgt nach der Nobilitierung des Autors und der Delegitimierung des ersten Herausgebers ein Apparat an gelehrsamen Quellenverweisen, der in einem eindrucksvollen, 72 Titel umfassenden Catalogo de los Avtores que han escrito de las Indias Orientales, Iapon, y China, y de sus situaciones, nauegacion, y conquistas kulminiert. Die Auflistung dieser Werke ist zwar schon deshalb kein wirklicher Beleg für die historische Richtigkeit der Erzählung Pintos, weil sie teilweise erst nach dessen Aufzeichnungen erschienen und deshalb nicht als Quellen gelten können; als Mittel zur apologetischen Autorisierung des Textes war sie jedoch zweifellos nicht wirkungslos. Dass die Verteidigung des Autors Pinto nicht um dessen selbst willen geschieht, sondern als Instrument im Dienste der Propaganda der spanischen Krone, bleibt dabei nicht verborgen. Das hagiographische Interesse an der Verbreitung der Wundertaten Franz Xavers wird zum Bestandteil einer Stilisierung der Habsburgermonarchie zur paniberischen und zugleich globalen Macht ${ }^{62}$, die als defensor fidei den katholischen Glauben sichert und dank der jesuistischen Missionierungen über die neue Welt verbreitet. Die

61 Zitiert wird im folgenden nach dem Druck der Erstausgabe: Historia oriental de las peregrinaciones de Fernan Mendez Pinto Portvgves, adonde se escriven muchas, y muy estrañas cosas que vio [...] Tradvzido de Portvgves en castellano por el Licenciado Francisco de Herrera Maldonado, Madrid: Tomas de Iunta, 1620. Zu Herreras Übersetzung des Textes vgl. auch Hans Joachim Simon, «Francisco de Herrera Maldonado - Apologet und Übersetzer von Mendes Pintos Peregrinação», in: Karl-Hermann Körner/Klaus Rühl (Hrsg.), Studia Iberica. Festschrift für Hans Flasche, Bern/München: Francke, 1973, S. 625-641; außerdem Teresa Cirillo, «Francisco de Herrera Maldonado Apologeta di Fernão Mendes Pinto», in: Quaderni Portoghesi 4 (1978), S. 183-198.

62 Dass die Globalisierung des Herrschaftsbereiches der Habsburgermonarchie dabei auch kulturelle Globalisierungseffekte zeitigte, die nicht als bloße kolonialistische Aneignung des Fremden zu beschreiben sind, hat Serge Gruzinski, Les quatre parties du monde: Histoire d'une mondialisation, Paris: Martinière, 2004, eindrucksvoll gezeigt. 
Überbietung der portugiesischen Originalausgabe an Rhetorik und Gelehrsamkeit durch Herrera Maldonado, der die «lengua Castellana» als «Reyna de todos los idiomas» (fol. $2 \mathrm{v}^{\circ}$ ) inthronisiert, stützt sich auf eine translatio imperii colonialis, die Fortführung der trabajos der «nacion Portuguesa gloriosa en dilatar la Fè Catolica en partes tan remotas» (fol. $2 \mathrm{r}^{\circ}$ ) durch die spanische Krone in ihrem «dilatado Imperio» (fol. $2 \mathrm{v}^{\circ}$ ), das sich dank der ehemals portugiesischen Besitztümer noch einmal dramatisch erweitert hat ${ }^{63}$.

Folgt man der Rhetorik Herrera Maldonados, wird Mendes Pintos Pilgerreise zu einem weiteren Dokument einer spezifisch katholischen Profanliteratur, wie sie für die spanische Gegenreformation kennzeichnend scheint. Anders als Villalba y Estaña im Peregrino curioso insistiert der Autor aber durchaus noch auf einer spirituellen Dimension des Pilgerschaftsgedankens, den er seinem Reisebericht mit der Semantik des Titels ja nicht grundlos voranstellt ${ }^{64}$. Die frühneuzeitliche empirische Erfahrung der Fremde und die kuriose Lust auf Exotisches und Neues ${ }^{65}$ treffen sich mit dem Bewusstsein des eigenen Fremdseins auf Erden als homo viator im tradierten christlichen Sinne ${ }^{66}$ und bilden gemeinsam den Rahmen, in dem sich die kritisch-satirische Stoßrichtung des Textes entfaltet. Über die Thematisierung der Religion gelingt es dem Erzähler immer wieder, das heroische Selbstverständnis, das

63 Teresa Cirillo, «Francisco de Herrera Maldonado» (Anm. 61), sieht die ideologische Funktion der Apologia Herreras ähnlich: «L'esaltazione in chiave confessionale dell'azione di Mendes Pinto costituisce, in un certo senso, il marchio di garanzia in una società in cui il topos dell'evangelizzazione è lo schermo ideologico che sorregge e giustifica gli eccessi perpetrati durante la conquista delle terre americane» (S. 190).

64 Dietrich Briesemeister bringt die komplexe Bedeutung der Titelsemantik auf den Punkt, wenn er formuliert: «Mit dem lakonischen Titel Peregrinaçam ruft Mendes Pinto einen großen Traditionszusammenhang auf und kann so mit mehrdeutigen Assoziationen spielen. [...] Prolog und Schlusswort deuten zwar die peregrinatio nach traditionellem Verständnis als Bußübung und Zeugnis göttlicher Führung, göttlicher Gnadenerweise, aber in diesem Rahmen entfaltet sich vor dem Auge des Leser verselbständigt ein recht unheiliges, heilloses Panorama menschlicher Verfehlungen, Schurkereien, Unvernunft, die der Überlebenskünstler zu überstehen hatte: eine Pervertierung der wundersamen Erscheinungen, die gemeinhin in erbaulichen Pilgerberichten zu finden sind»; vgl. «Die wunderlichen und merkwürdigen Reisen des Fernão Mendes Pinto (1537-1558) im fernen Osten», in: Xenja von Ertzdorff (Hrsg.), Beschreibung der Welt. Zur Poetik der Reise- und Länderberichte., Amsterdam u. a.: Rodopi, 2000, S. 299-313, hier S. 307.

65 Im Vorwort «ao Leitor» wird das Interesse des Lesers an «cousas myto nouas \& peregrinas» dabei ausdrücklich als Bewunderung des Reichtums der Schöpfung Gottes gerechtfertigt, eine Legitimation, die für die rein innerpeninsuläre Reise von Villalba y Estañas peregrino curioso nicht angeführt werden konnte.

66 Dieses Bewusstsein stellt der Erzähler gleich zu Beginn seiner Erzählung aus: «Qvando às vezes ponho dianto dos olhos os muitos \& grandes trabalhos $\&$ infortunios que por mim passarão, começados no principio da minha primeira idade, \& continaudos pella meiyor parte, \& milhor tempo da minha vida, acho que com muita razão me posso queixar da ventura que parece que tomou por particular tenção e empresa sua perseguir-me e maltratarme $[\ldots]$. Mas por outra parte quando vejo que do meyo de todos estes perigos $\&$ trabalhos me quis Deos tirar sempre em saluo, \& porme em seguro, acho que não tenho tanta razão de me queixar por todos os males passados, quanta de lhe dar graças por este so bem presente, pois me quis conseruar a vida [...]» (fol. I). 
den offiziellen Kolonialdiskurs seiner Zeit bestimmt ${ }^{67}$, ironisch zu brechen, wie vor allem Rebecca Catz in ihrer Studie betont hat ${ }^{68}$. Während der gottgegebene missionarische «Auftrag» als frommer Grund der Reisen in den fernen Osten vor allem in den Episoden um den Freibeuter António Farias (Kap. 38-78) in krassen Kontrast zu einer kolonialistischen Praxis gewaltsamer Ausbeutung tritt, die von skrupellosem materialistischem Gewinnstreben getragen ist ${ }^{69}$, und die 〈Religion〉 der Christen dabei als bloße Ideologie und zynisch-legitimatorische Rhetorik bloßgestellt wird, ist Religion auf der 〈anderen〉 Seite insgesamt eher als eine Form der Lebenspraxis dargestellt, der der Erzähler zwiespältig gegenübersteht: $\mathrm{Ob}$ in den Rahmen einer eindrucksvoll geordneten Zivilisation integriert (China und dessen Kapitale Peking ${ }^{70}$ ) oder als volkstümlicher Fanatismus (in der Darstellung von religiösen Opferritualen in Calaminham, Kap. 161) ${ }^{71}$, immer wird sie als ethische, das Handeln der Menschen bestimmende Größe anschaulich gemacht, wobei die Form der Darstellung von einer «Ambivalenz zwischen Verdammung des

67 Dieser Diskurs klingt auch im Vorwort des Textes an, wenn von der «myta gloria \& honra do nome \& nação Portuguesa a custa do sangue que muytas vezes derramou pelejando pela Fè com os inimigos della» die Rede ist.

68 Vgl. Rebecca Catz, Fernão Mendes Pinto. Sátira e anti-cruzada na «Peregrinação», Lisboa: Instituto de Cultura e Lingua Portuguesa, 1981. Die Autorin vertieft damit die Richtung, die bereits António José Saraiva vorgegeben hatte, als er Pintos Text als protopikarische Satire interpretierte (Fernão Mendes Pinto ou a Sátira Picaresca da Ideologia Senhorial, Lisboa: Jornal do Foro, 1958) und die sie selbst in ihrer vorangehenden Studie, $A$ sátira social de Fernão Mendes Pinto, Lisboa: Prelo, 1978, eingeschlagen hatte. Die von Saraiva und Catz vertretene These einer satirischen Funktion des Textes ist nicht unwidersprochen geblieben. Die teilweise polemisch geführte Forschungsdiskussion fasst Jens Reck, «Eine ambivalente Repräsentation des Fremden», in: Doris Bachmann-Medick (Hrsg.), Übersetzung als Repräsentation fremder Kulturen, Berlin: Schmidt, 1997, S. $21-$ 41, hier: S. 33-35, zusammen. Reck selbst schließt sich dabei dem Ansatz von Catz an.

69 Vgl. Catz, Fernão Mendes Pinto (Anm. 68), S. 34-64, die die Episoden als eine Struktureinheit interpretiert, die als «paródia da espansão ultramarina portuguesa e da ideologia da cruzada» funktioniere (S. 34).

70 In der Darstellung Pekings als musterhaft geordneter Stadt wird ausdrücklich auch die wichtige Rolle der Religion betont, die dabei jedoch als «falsche» Vielgötterei markiert wird: «mil \& oitocentas casas dos seus pagodes, em que continuamente se sacrifica huma muyto grande quantidade de aues, \& de animais siluestres dando por razão que aqueles sao mais aceitos a Deos que os outros domesticos que a gente cria em casa, $\&$ para isto dão os sacerdotes muytas razões ao pouo, com que o persaudem a terem esta abusão por artigo de fe. Destes pagodes que digo ha muytos edificios muyto sumptuosos, principalmente os das religiões em que vieuem os menigrepos \& conquiais \& talagrepos, que são os sacerdotes das quatro feitas de Xaca, \& Anuda, \& Gizom, \& Canom, as quais precedem por antiguidades as outras trinta $\&$ duas deste diabolico laberinto em que o demonio se lhes mostra algumas vezes em diuersas figuras, para os fazer dar mais credito a estes seus enganos \& falsidades» (fol. $125 \mathrm{v}^{\circ}$ ).

71 Schurhammer stufte die Reise nach Calimanham als «sicher erdichtet» ein; vgl. «Fernão Mendes Pinto und seine Peregrinaçam» (Anm. 58), S. 98. Pinto könnte dabei die Schilderung des Juggernaut-Festes mit seinen Opferriten aus dem Reisebericht des Odoricus de Pordenone übernommen haben. 
Fremden und versteckter Bewunderung für die Intensität einer fremden Religiosität» zeugt ${ }^{72}$.

Die Passagen, die gegen Schluss des Buches das Wirken des Jesuitenmissionars Pater Franz Xaver darstellen, stehen einer solchen satirischreligionskritischen Lektüre der Peregrinação nur scheinbar entgegen. Bei genauem Hinsehen zeigt sich gerade an ihnen eine bemerkenswerte Ambivalenztaktik des Ich-Erzählers, die ihn zu einem Vorläufer und Verwandten der unglaubwürdigen pikarischen Erzähler werden lässt ${ }^{73}$. Erzählerische Ambivalenz sorgt dafür, dass die im Text gelieferten Informationen zum frommen Wirken und den «Wundern» des Jesuitenmissionars zwar für hagiographische Zwecke eingesetzt werden konnten, zugleich aber auch die Möglichkeit zur Infragestellung des Hagiographischen bieten und sich ironisch wenden lassen, wie es die Interpretation von Rebecca Catz vorgeführt hat ${ }^{74}$. Über Ernst oder Ironie der Darstellung des christlichen Heiligen lässt sich deshalb kaum eindeutig mit textinternen Kriterien entscheiden, weil der Erzähler sich gerade hier auf die Position eines naiven und weitgehend unbeteiligten Berichterstatters zurückzieht. Ohne formal die Exemplarität des Missionars zu bestreiten, liefert der Erzähler wie absichtslos Informationen, die zu einer Destruktion der hagiographischen Absicht genutzt werden können, etwa wenn er von den Misslichkeiten berichtet, die dem Pater daraus erwachsen, dass tragende Elemente aus dem lateinisch-portugiesischen Vokabular des Heiligen, «Deos» und «sancte», leicht mit ganz unheiligen japanischen Wörtern zu verwechseln sind und seine Predigten deshalb von seinen Gegnern als Profanierungen ausgelegt werden können ${ }^{75}$. Wer Böses von solchen Berichten

72 Hermann Krapoth, «Das Fremde im Spinnennetz der eigenen Kultur», in: Beata Hammerschmidt (Hrsg.), Übersetzung als kultureller Prozess. Rezeption, Projektion und Konstruktion des Fremden, Berlin: Schmidt, 1998, S.177-212, S. 187 f. Die Formulierung, die Krapoth mit Blick auf die Darstellung des Opferfestes in Calimanham verwendet, scheint mir für die Darstellung fremder Religiösität in der Peregrinação insgesamt gültig. Diese Ambivalenz dem Fremden gegenüber verwischt auch die mögliche satirische Intention des Textes, denn die fremde Kultur wird nicht einfach nur als ein Kontrastmittel zur Negativierung des Eigenen eingesetzt, wie es Rebecca Catz in ihrer Lektüre betont, sondern hat an vielen Stellen auch einen durchaus eigenständigen, nicht satirisch funktionalisierten Status, als Objekt einer von Angstlust geprägten Faszination.

73 Die Nähe des Erzählers zu den Strategien pikarischen Erzählens betonte schon Saraiva (Anm. 68), ohne dabei eine direkte Filiationslinie zwischen Pintos Text und dem Lazarillo zu behaupten. Die These wurde dann vor allem von Ulla M. Trullemans aufgegriffen und modifiziert: «Peregrinação de Fernão Mendes Pinto, obra spícara de la literatura portuguesa ?», in: Huellas de la picaresca en Portugal, Madrid: Insula, 1969, S. 77-101. Rebecca Catz sieht den Pícaro als eine der vier narrativen personae, die der Erzähler im Text ausspielt: «Vir Bonus», «Ingénu», «Defesor da fé» und eben «Pícaro»; vgl. A sátira social (Anm. 68), S. 115-155.

74 Catz, Fernão Mendes Pinto (Anm. 68), S. 91-115.

75 Vgl. Kap. 213, «De tudo o mais que o padre passou com estes bonzos atê se embarcar para a China». Zunächst wird darauf hingewiesen, dass der Name Gottes, den der Jesuitenpater in seiner Predigt natürlich anführt, im Munde der Japaner einen ganz anderen Sinn bekommt, nämlich den der Lüge, was die Bonzen zur Diffamierung des Paters nutzen: «se ha de saber 
über Pannen in der Missionierungsarbeit denkt, muss dem Erzähler allerdings eine böse, das Heilige desakkreditierende Absicht erst unterstellen. Er produziert mögliche Zweifel an der Wirksamkeit des Heiligen ja nicht offensivkritisch, sondern durch naives Ignorieren der Schlussfolgerungen, die sich aus seinen Informationen ziehen lassen ${ }^{76}$. Er stellt die eigene Ignoranz dabei mehrfach als gläubiges Unwissen aus und macht seine erzählerische Macht über das Faktische klein, indem er auf das unendlich überlegene Wissen Gottes und dessen Providenz verweist. So begnügt er sich beispielsweise nicht damit, die positiven Effekte aufzuführen, die Franz Xaver auf den «rey de Bungo» ausübt, sondern wundert sich, dass dessen guter Einfluss nicht von einer abschließenden erfolgreichen Konversion des Königs gekrönt wurde, was er nur unter Verweis auf die unerforschliche und menschlichem Wissen überlegene Weisheit Gottes erklären kann:

E assi defendeo mais outras cousas da mesma maneyra destas, dizendo aos seus mytas vezes em publico, que no rosto do padre, como em hum espelho claro se estaua enuergonhando \& confundindo do que até então tinha seguido por conselho dos bonzos, pelos que nos pareceo sempre, segundo o muyto disto que nelle viamos, que aueria pouco que fazer em se elle conuerter á Fé, se este bemauenturado o conuersara mais tempo, mas como a tenção del Rey estaua posta em fito muyto differente desta facilidade em que o nosso juizo muytas vezes se embaraça, não ouue effeito este negocio de sua conuersão até o dia de oje, mas o segredo disto so Deos o entende, que os homens nem restejallo podem. (fol. 277 v.)

Die scheinbar leicht zu bewerkstelligende, aber nicht erreichte Konversion steht plötzlich im Kontrast zur zuvor erwähnten erfolgreichen Konversion des Bonzen von Canafama, die in der spanischen Übersetzung noch zur «famosa [...] conuersion» gesteigert wird und als ein Beispiel für die eficacia des jesuitischen Missionars herhält, «siervo de Dios al aumento de nuestra Fè Catolica, conuirtiendo inumerables de aquellas gentes» (444). Sicher unwillentlich

que na lingoa do Iapão se chama a mentira diusa, \& porque o padre quando pregaua dezia que aquella ley que elle vinha denunciar era a verdadeyra ley de Deos, o qual nome elles pela grossaria da sua lingoa não podião pronunciar tão claro como nos \& por dizeren aos seus que o padre era demonio em carne que vinha infamar a Deos pondolhe nome de mentiroso.» (fol. $283 \mathrm{r}^{\circ}$ ). In eine ähnliche metonymische Verbindung zum Heillosen gerät sancte: «E porque tambem este vocablo santi na lingoa Iapoa he torpe \& infame, daquy veyo arguyr este ao padre que punha maos nomes aos Sãtos», was Franz Xaver dazu veranlasst, sancte als Attribut der Heiligen in seinen Predigten durch beate zu ersetzen (fol. $283 \mathrm{v}^{\circ}$ ). Rebecca Catz treibt die hier aus der Not geborene Degradierung des Heiligen noch weiter, wenn sie maliziös die Frage stellt, welchen Ersatzterminus der Prediger denn wohl für Deos gefunden haben könnte; vgl. Fernão Mendes Pinto (Anm. 68), S. 110.

76 Die Strategie, «Signale des Naiven» als «Verhüllungen einer «eigentlichen» Aussageabsicht, die wesentlicher Ausdruck der Kritik ist», beschreibt auch Reck, «Eine ambivalente Repräsentation des Fremden» (Anm. 68), S. 37 f., am Beispiel der Rede eines einheimischen Jungen auf der «Ilha dos Ladrões». Was dort noch strategischer Einsatz einer Fremdperspektive war, würde nun zu einer Strategie der Selbstpräsentation des Erzählers im Stile von Erasmus' Moria, die Kritik nur deshalb zu formulieren vermag, weil sie keinen Anspruch auf die Wahrheit erhebt. 
macht Herrera Maldonado mit seinen hyperbolischen Zusätzen nur die Frage nach den Gründen für das Abreißen der missionarischen Erfolgsgeschichte ausgerechnet an der obersten und entscheidenden Stelle der Macht und bei einem König, der doch offensichtlich zu besserer Einsicht und humanem Verhalten fähig ist, noch drängender. Der Versuch zu einer Steigerung des Hagiographischen in der übersetzerischen Vereinnahmung des portugiesischen Originals verstärkt zugleich den Widerstand dagegen, den Pinto mit seinem (gespielt oder echt) naiven Staunen über die nicht erfolgte Bekehrung eingebaut hat.

Ähnlich, ebenfalls durch den Verweis auf Gottes übermächtiges Wissen, das an einer entscheidenden Informationslücke des Erzählers aufgerufen wird, wird auch später Zweifel an dessen 〈ehrlicher〉 hagiographischer Absicht genährt, wenn es im Kap. 216 vom Begräbnis Franz Xavers zunächst hieß, es habe «grande sentimento de todos» ausgelöst, «principalmente dos mais virtuosos \& tementes a Deos», um dann sofort einzuschränken, dass vielleicht doch keine allgemeine Trauer geherrscht habe, was aber letztlich nur der Allmächtige wissen könne:

porem não faltarão alguns em que este sentimento se não enxergou de foro, se de dentro o tinhão ou não, Deos o sabe, elle os julgue que sabe a verdade das cousas, $\&$ as razões dellas, mas o que se soube publicamente foy que daly a quinze dias escreuendo hum homen, que por sua honra não nomeyo, huma carta a dom Aluaro [...] num dos capitolos della lhe disse secamente, câ morreo mestre Francisco, mas na sua morte não fez milagre (fol. $289 \mathrm{r}^{\circ}$ )

Eine hagiographische Lesart wird darauf insistieren, dass der Zweifel an der Wundertätigkeit von «mestre Francisco» hier nur deshalb erwähnt wird, damit dann mit der Ausgrabung seines unverwesten Leichnams die öffentliche Bekehrung der vormals Ungläubigen «com muytas bofetadas» und «muytas lagrimas» (fol. $298 \mathrm{r}^{\circ}$ ) umso wirkungsvoller inszeniert werden könne. Dieses funktionale Ziel einer Kontrastbildung zwischen Unglauben und Glauben zur Profilierung des Wunders wäre aber allein durch die Erwähnung des Briefinhaltes erreichbar. Die andere vom Erzähler aufgeworfene Frage, die nach der Korrespondenz von innerem Fühlen und den äußeren Zeichen des Gefühlten, nach der Ehrlichkeit von Tränen, bleibt damit aber bestehen und taucht die beschriebenen emphatischen Gefühlsausbrüche der angesichts des inkorrupten Leichnams 〈Bekehrten〉 in einen Zweifel, über den sich nicht wirklich entscheiden lässt ${ }^{77}$, sondern der dem Leser als potentielle Möglich-

77 Rebecca Catz, die eine möglichst eindeutige satirische Funktion des Textes nachweisen und insofern ebenfalls die Ambivalenz des Textes entscheiden will, übergeht bei der Besprechung dieses Kapitels die von mir hervorgehobene Stelle, bringt dafür aber das Wunder des unkorrupten Leichnams mit Kap. 127 in Verbindung, wo von Balsamierungstechniken die Rede war, um so das Wunder entzaubern zu können. 
keit gelassen wird, eben weil der Erzähler ausdrücklich die Entscheidung im Namen Gottes suspendiert hat ${ }^{78}$.

Die 〈Modernität) dieses frühneuzeitlichen Textes liegt wahrscheinlich genau in dieser uneindeutigen Haltung zum Glauben, die sich durch die erzählerische Form einer sich in unterschiedliche Masken kleidenden uneindeutigen Erzählinstanz artikuliert. Die eigentlichen Absichten dieser wechelhaften Person, die in vielen personae auftritt, können nur vermutet werden, weil sie mehreren Zwecken zugleich zuzuarbeiten scheint, allen voran dem der Satire (die in der ersten Hälfte dominant wirksam ist) und dem der Hagiographie (mit der Einführung Franz Xavers gegen Ende des Textes). Dem erzählenden Ich kann man in keiner seiner Rollen ganz, aber auch nicht einfach gar nicht glauben ${ }^{79}$. Das zwischen totaler Akkreditierung und totaler Desakkreditierung liegende Möglichkeitsfeld erweitert sich nur noch, wenn man die wechselhafte Biographie seines Autors kennt, der vom reichen Händler zum armen Jesuiten wurde und dann wieder zum Privatmann, der mit und gegen die Interessen der Societas wohl zuallererst den eigenen Nachruhm zu befördern suchte und dabei taktisch agieren musste ${ }^{80}$.

78 In diesem Falle erreicht die spanische Übersetzung nun allerdings eine weitgehende Aufhebung des Zweifels über die «wahren» Gefühle der Beteiligten durch entsprechenden Ausbau der Stelle und Ausblendung der aktiven Rolle des Erzählers als Informationsvermittler, der bestimmte Informationen bewusst vorenthält (z. B. den Namen des Zweiflers, den er «dessen Ehre zuliebe» nicht nennen will, was ja an sich schon eine ziemlich merkwürdige Formulierung ist): «aunque es ansi que huuo algunos, que encubrian muy bien el sentimiento que publicauan, Dios solo juzga de los secretos del coraçon, y su Magestad solo mira descubiertas las intenciones de los hombres, si bien algunos se les echaua de ver la mala suya, publicamente pues de alli à quinze dias escriuiendo á Don Aluaro de Atayde con vn varcon que partia de la China à Malaca, vn hombre que por su autoridad calló quien era, en vno de los capitulos de su carta dezi ansi secamente: Aqui murio el maestro Francisco, y en su muerte no hizo milagro» (S. 426). Die Übersetzung arbeitet insgesamt also an einer Ambivalenzreduktion des Originals, die jedoch nicht in allen Fällen erfolgreich ist.

79 Paul Teyssier formuliert diesen Charakter einer relativen Glaubwürdigkeit ähnlich: «Il est impossible de croire tout à fait à tout ce qu'il raconte, mais en même temps il est impossible de ne pas y croire un peu, en raison de la précision et de l'exactitude de certaines des informations qu'il nous donne sur la lointaine Asie»; «L'envers de l'épopée», in: Critique 44 (1988), S. $495-496$ u. 676-683, hier S. 682.

80 Noch komplizierter wird die Einschätzung möglicher biographischer Motivationen, wenn man die These der Herkunft Pintos aus einer converso-Familie miteinbezieht. Sie ist schon von Armando Cortesão Cortesão («Fernão Mendes Pinto Não Era de Origem Judaica», in: Seara Nova Nr. 842, 2 Okt. 1943, S. 89-91) entschieden bestritten worden, mit Blick auf die theatralische Bearbeitung des Stoffes der Peregrinaçao durch Antonio Eniquez Gómez hat Constance Hubbard Rose sie aber noch einmal aufgegriffen, zusammen mit den damit verbundenen Spekulationen über einen unfreiwilligen Austritt Pintos aus dem Jesuitenorden: «Perhaps the threat of statues concerning «limpieza de sangre» necessitated his separation form the «Compañia〉. Since Portuguese Jesuits were prominent in pressing Loyola to impose such restrictions, it would have been an act of folly for Fernão Mendes Pinto to return home as a Portuguese cleric of New Christian ancestry; yet the establishment of the Inquisiton in Goa was inminent and indeed became fact in 1560. Mendes Pinto returned to 
Mit den beiden vorangehend analysierten literarischen Funktionalisierungen des peregrinatio-Konzeptes teilt Pintos Text den Charakter einer Literatur inter fanum et profanum, in der die Schwelle zwischen Heiligem und Profanem zum Problem erhoben und der komplexe Prozess der Schwellenbildung sichtbar gemacht wird. Weit davon entfernt, bloß als Verlängerungen der theologischen Doxa des nachtridentinischen Katholizismus zu dienen, zeugen die drei untersuchten Texte von ideologisch-narrativer Kompromissbildung, wie sie für den Versuch zur Ausbildung einer katholischen Profanliteratur in Spanien typisch scheint. Ob der Fragment gebliebene protoliterarische Peregrino curioso, die verdoppelte und mit zwei konkurrierenden Enden versehene Selva de aventuras oder die lange Zeit vor der Schwelle zur Publikation verharrende und erst dank einer entsprechenden Interessenlage und vielleicht sogar nach Eingriffen fremder Hand publizierte Peregrinação: alle drei Beispiele, die für die Forschung heute eher marginalen Wert zu haben scheinen, sind gerade in ihrer uneinheitlichen Gestalt symptomatische kulturhistorische Zeugnisse. Ihre Verfassung ist nicht nur von einer gattungs- oder sujetimmanenten Innenpragmatik bestimmt, sondern auch von der Außenpragmatik gesellschaftlicher Wert- und Normenbildung. Auf je eigene Weise tragen sie eine fremde, heteronome Logik in sich, die sie offen und unabgeschlossen hält und nicht zum 〈organischen〉 Werk gerinnen lässt. In diesem Sinne handeln sie nicht nur von der Idee der peregrinatio, sondern sind zugleich kuriose Texte, die man im frühneuzeitlichen Spanien mit Recht und in vollem Wortsinne peregrinos genannt hätte.

Portugal as a private citizen in 1558»; vgl. «Antonio Eniquez Gómez and the literature of exile», in: Romanische Forschungen 85 (1973), S. 63-77, hier S. 68 f. 